\title{
IDEAS PARA UNA REFORMA DEL COMPONENTE LEGAL RELACIONADO CON LA TIPOLOGÍA DE LAS INSTITUCIONES DE EDUCACIÓN SUPERIOR
}

\author{
Luis EnRIQue Orozco SiLVA*
}

\begin{abstract}
*Licenciado en filosofía y Letras de la Pontificia Universidad Javeriana y PH. D. en filosofía de la Universidad de Lovaina (Bélgica). Es profesor Titular y Director del Area de Gestión y Políticas Públicas de la Facultad de Administración de la Universidad de los Andes; se desempeña como Director de la Cátedra de Educación Superior para América Latina. Fue Coordinador del Consejo Nacional de Acreditación (CNA) y miembro de la Sala Institucional y de Maestrías y doctorados del Ministerio de Educación Nacional. Entre sus publicaciones últimas figuran: La educación superior, problema global y respuesta Nacional (2001).Dinámicas de transformación de la Educación Suprior (2005); La política de cobertura. Eje de la revolución educativa, 2002-2008 (2009). Universidad de los Andes. Bogotá. Colombia. E-mail: leorozco@uniandes.edu.co
\end{abstract}

Resumen: El autor plantea que un aspecto central de la reforma de la educación superior en curso debe consistir en un replanteamiento de la tipología de las instituciones que ofrecen el servicio de la educación de tercer nivel. Ello traería dos ventajas básicas; de una parte, que la oferta educativa sea clara para las demandas que atiende; $y$ de otra, que cada institución posea una identidad académica precisa y según la modalidad académica que ofrece. Con la situación actual hay confusión para el mercado y poca claridad hacia adentro del sistema contribuyendo con ello a la asimetría del mercado de la Educación Superior. Sobre la base de un diagnóstico sobre el comportamiento del sistema en los últimos veinte años propone una alternativa para la política pública que se configura en el momento en Colombia.

Palabras clave: Tipologías. Sistema de educación superior. Diversificación.

\section{IDEAS FOR A REFORM OF THE LEGAL COMPONENTS RELATED TO THE TYPE OF HIGHER EDUCATION INSTITUTIONS (HEI)}

Abstract: The author proposes that a central aspect of the reform of the higher education system under current review must consider how the types of higher education institutions are determined. Doing such a review has two advantages: making clear the educational offer based on the demands of the system, and, that every institution has a precise academic identity and academic modality. The actual situation is confusing for the market and contributes to its asymmetry. The author's proposal is based on a systematic review and diagnosis of the higher education system that covers the last 20 years and contributes with some critical ideas to the construction of a public policy for the higher education system in Colombia.

Keywords: Types. Higher education system. Diversification.

\section{IDEIAS PARA UMA REFORMA DO COMPONENTE LEGAL RELACIONADO COM A TIPOLOGIA DAS INSTITUIÇÕES DE EDUCAÇÃO SUPERIOR}

Resumo: O autor propõe que um aspecto central da reforma da educação superior deve consistir numa reelaboração da tipologia das instituições que oferecem o serviço da educação de terceiro nível. Isso traria duas vantagens básicas: de uma parte, que a oferta educativa seja clara para as demandas que atende; e de outra, que cada instituição possua uma identidade acadêmica precisa e segundo a modalidade acadêmica que oferece. Com a situação atual há confusão para o mercado e pouca clareza para o interior do sistema contribuindo com isso à assimetria do mercado da Educação Superior. Sobre a base de um diagnóstico a respeito do comportamento do sistema nos últimos vinte anos, propõe uma alternativa para a política pública que se configura no momento na Colômbia.

Palavras-chave: Tipologias. Sistema de educação superior. Diversificação. 


\section{INTRODUCCIÓN}

El texto que sigue busca presentar elementos de juicio para los ajustes que el gobierno considere pertinentes de incluir en los cambios a la Ley 30 de 1992 en materia de la tipología de las instituciones. Estos elementos han de ser validados por los agentes del sector con el interés de buscar los consensos necesarios que otorguen legitimidad a las ideas aquí expuestas. El país ha venido ofreciendo análisis y consideraciones sobre este tópico a lo largo del período de vigencia de la Ley; algunos de ellos, producto de la reflexión sistemática de expertos y otros que han surgido en el proceso de la discusión sobre el tema en diferentes momentos que bien vale la pena tener en cuenta (OROZCO SILVA, 2001a) ${ }^{1}$. De igual modo, debe precisarse que lo relacionado con la tipología de las instituciones no constituye el cuerpo central de la reforma de la Ley 30 pero sí es determinante por cuanto en la definición de las instituciones que integran el Sistema de Educación Superior se hace evidente una concepción del servicio público de tercer nivel, de los propósitos y objetivos que se quiere que cumplan las IES y del tipo de relación deseable entre éstas y el Estado; aspectos que son centrales en la reforma. Este texto aborda solamente un tópico, consciente de la complejidad y grado de desarrollo que implicaría una reforma integral de la norma.

Aunque el interés por el tema de la formación práctica en el país es tan antiguo como la fundación de la República, desde 1975 se comenzó a incluir el nivel técnico y tecnológico en la denominada educación postsecundaria o superior. En el Decreto 80/80 la incorporación se hizo definitiva. Este Decreto reviste la mayor importancia porque estableció por primera vez la tipología de instituciones que se encuentra vigente y lo hizo sobre la base de la definición de "modalidades de formación" según lo estableció el Documento Base sobre el cual se desarrolló su articulado².

1 Fabio Lozano Santos (2000) Estructuración de anteproyectos de reforma legal para el sector de la educación superior. ICFES. Bogotá. Blanca Lilia Caro (1993) Autonomía y calidad. Ejes de la reforma de la educación superior en Colombia. Universidad Nacional y Universidad de los Andes. Bogotá. ICFES (1997) Educación técnica y tecnológica en Colombia. Diagnóstico y recomendaciones de política. Bogotá. Víctor Manuel Gómez "Hacia la diferenciación y la especialización en la educación superior. Propuesta para el caso de Colombia. En: Educación Superior y Sociedad. v.2, n. 2. Bogotá. Gabriel Misas (1990) Notas para la formulación de un plan de desarrollo de la educación superior: modalidades técnica y tecnológica. Bogotá. ICFES-ASCUN (1997) Evolución y estado actual del pensamiento sobre educación técnica y tecnológica de nivel superior en Colombia. En diversas ocasiones este tema ha sido objeto de discusión nacional. Para mencionar algunas, de especial significación, recuérdese cuando en 1986 se hizo la discusión de la "educación por ciclos" o, cuando se conformó la Misión de ciencia y tecnología en 1988. Los planteamientos hechos en el texto recogen lo señalado por los autores y comisiones últimas.

2 Es importante señalar que el ICFES ya había presentado en 1974 una definición de la 
Ahora bien, antes de la formulación de la Ley 30 de 1992 también se elaboró un Documento Base en el cual se hicieron visibles las consecuencias positivas del ordenamiento anterior y se recogieron los efectos negativos que según las mismas instituciones estaban siendo críticos para la buena marcha del sistema, para la consolidación e incremento de las modalidades tanto como sobre las implicaciones para el ejercicio de la autonomía de las instituciones, reconocida de modo exclusivo para las universidades en la Carta Política de 1991(OROZCO SILVA, 1990).

En la actualidad, existe la inquietud en torno a las limitaciones que aún presenta esta tipología en el caso colombiano para efectos de disponer de un sistema lo más diversificado posible, flexible, y que realmente ostente las características de un sistema en el cual las instituciones de educación superior (IES) tienen funciones comunes pero diferenciadas en función de los retos diferentes que deben atender tanto desde el punto de vista del conocimiento como de la pertinencia, calidad y expectativas de la sociedad frente a ellas.

De modo paulatino los dos últimos gobiernos han venido ajustando la Ley 30 en aspectos centrales para encausar el esfuerzo de todos los agentes del sector en orden a construir un sistema dinámico que pueda enfrentar los retos actuales que el contexto impone. En esta última dirección, se entiende el porqué de los decretos relacionados con el registro calificado, la educación por ciclos propedéuticos, el fomento a la flexibilidad, el esfuerzo por consolidar la formación técnica y tecnológica (Ley 749 de 2002) y la intensidad con que se ha trabajado en el programa de las bolsas concursables que fomenta la vinculación y el compromiso del sector privado con la educación superior en el nivel regional.

De igual modo, las instituciones han hecho esfuerzos importantes y de diversa magnitud por consolidar y acreditar los logros alcanzados. Naturalmente, que todos estos ajustes se han hecho en el marco de una política pública centrada en el incremento de la cobertura, eje de la política educativa del gobierno actual ${ }^{3}$.

El texto que sigue se centra en el tema de la tipología actual de las instituciones y comprende en primer lugar, un diagnóstico de la situación del sistema

educación tecnológica en la cual esta modalidad se separaba totalmente de la ingeniería entendiéndola como la fase culminante de la educación vocacional. A su vez, las instituciones que brindaban este tipo de formación se agremiaron en ACIET desde 1972 y a partir de dicha Asociación el tecnólogo era definido como un Técnico superior. Para un análisis en detalle de la evolución de este concepto y de las modalidades que posteriormente se recogieron en el Decreto 80 de 1980, véase: ICFES-ASCUN (1997) con planteamientos hechos por ICFES-ASCUN (1997) Evolución y Estado actual del pensamiento sobre educación técnica y tecnológica de ivel superior en Colombia (1997). Corcas Edits.

3 Para un análisis en detalle de la política de cobertura en los últimos ocho años, véase: Luis Enrique Orozco Silva y Otros (2009). 
visto a través de algunos indicadores, hecho con el fin de contextualizar el alcance de los cambios posibles, el comportamiento de las modalidades técnica y tecnológica, así como también de la universitaria ${ }^{4}$. En él se hace un énfasis especial en las modalidades técnica y tecnológica por ser ellas sobre las que recae el mayor efecto de las sugerencias hechas. Esta parte se cierra con unas consideraciones sobre los aspectos que están en juego en el diagnóstico para todos los tipos de institución y que exigen un cambio importante en la normatividad existente en lo relacionado con la tipología que tiene la Ley 30 de 1992

En segundo lugar, se muestra una propuesta de ordenamiento de las instituciones a partir de la oferta educativa del tercer nivel. Para presentarla, se describe primero el ámbito normativo de los ajustes que cubre la primera parte de la actual Ley 30 de 1992 en sus capítulos de dos a seis; y, luego, se presenta tanto el cuerpo de la propuesta y sus implicaciones jurídicas para los ajustes posibles como las externalidades positivas que tiene ésta para todo el sistema ${ }^{5}$.

En la bibliografía se muestra una literatura más amplia que la citada y en la que el Autor se ha basado con el ánimo de fundamentar y presentar elementos para la discusión actual.

\section{DIAGNÓSTICO}

El diagnóstico requerido implica tener en cuenta tres dimensiones: la dinámica del Sistema de Educación Superior en la actualidad, el comportamiento de las modalidades durante el período de vigencia de la Ley 30 de 1992 con énfasis en las modalidades técnica y tecnológica, y los nuevos escenarios y retos que tienen las universidades en el presente y hacia el futuro inmediato.

\subsection{La dinámica del Sistema de Educación Superior en la actualidad.}

En relación con el comportamiento del sistema en su conjunto es importante tomar algunos indicadores relacionados con: a- El tamaño de la matrícula;

4 Los indicadores que se toman son aquellos que permiten entender mejor el problema de la tipología de las instituciones y no del Sistema de Educación Superior en su totalidad. Análisis que el Autor ha efectuado en otros textos. Véase: Luis Enrique Orozco y Otros (2009).

5 Se ha querido evitar demasiadas cifras en forma de gráficos y tablas para no sobrecargar el texto, salvo en los casos que se consideran más críticos en razón de su significado y alcance para el trabajo. En la elaboración del texto se ha tenido en cuenta las sugerencias hechas por diversos miembros de la comunidad académica del país en reuniones y eventos hechos por ASCUN y de modo especial los comentarios de los especialistas y lectores del Documento en su versión inicial, especialmente los trabajos de Víctor Manuel Gómez cuyos estudios sobre la educación técnica y tecnológica han sido seguidos por el Autor de este texto; de igual modo, el Autor ha cuidado de recoger las sugerencias de los lectores designados por ASCUN para hacer una mirada crítica de la versión inicial del Documento: José Germán López Quintero y Jairo Cifuentes Madrid. 
b- la participación de los distintos tipos de instituciones en dicha matrícula; c- la relación entre los tipos de formación que se ofrecen en las instituciones y las demandas de los mercados laborales; d- la tasa de cobertura actual y e- la deserción que tiene el Sistema de Educación Superior.

a) El Sistema de Educación colombiano ha evolucionado de tener un tamaño mediano, a uno grande con una matrícula que para el 2008 ascendía a 1.444.544 estudiantes. Entre 2002 y el 2008 se ha tenido un crecimiento constante pero moderado de la matrícula. El crecimiento promedio para el mismo período fue del 6\% aproximadamente. Un aspecto importante del comportamiento de la matrícula en los últimos años tiene que ver con la distribución de la misma según origen, puesto que la matrícula del sector público que venía disminuyendo, ha tenido una franca recuperación con un incremento de su participación del $41 \%$ en el 2002, al 55\% en el 2007 frente a un sector privado que disminuye, con una participación que si bien en el 2.000 es del $64 \%$ pasa al $45 \%$ en el 2007 . Es posible que entre otras razones el esfuerzo del gobierno por ampliar cobertura a través de una reorientación del crédito educativo orientado a los estratos de menores ingresos, a través del Programa de Acceso con Calidad a la Educación Superior (ACCES) haya producido algún efecto positivo en esta evolución de la matrícula del sector público; lo mismo podría decirse del aporte de las universidades públicas al aumento de cobertura y la acción del SENA, cuya matrícula asciende en la actualidad a cerca de 500.000 estudiantes.

Según la evaluación de este programa realizada en el 2009, es importante observar que si se analiza el porcentaje de los créditos nuevos otorgados según carácter de las IES, la mayor demanda proviene de la educación universitaria. En efecto, las universidades presentan el mayor número en el porcentaje de participación. En el período entre el primer semestre de 2003 y el segundo semestre de 2007, los estudiantes de las universidades obtuvieron el 53\% y $64 \%$ del total de los créditos respectivamente. Las instituciones universitarias son el segundo grupo de IES según carácter en participación con respecto al total representando entre el $22 \%$ y el $34 \%$ del total. Las IES técnicas y tecnológicas, por el contrario, presentan una participación que en general no supera el 10\% de los créditos. ${ }^{6}$

b) Esta matrícula se distribuía en los diferentes tipos de instituciones. Si se observa su número por modalidades, éste no ha cambiado significativamente

6 En general, la tasa bruta de cobertura para el período comprendido entre 2002-2007 varía entre el $24.47 \%$ y el $32.48 \%$, lo que significa que para el último año estudiado 3.3 de cada 10 personas están asistiendo a la educación superior. En grandes números este aporte sobrepasa los 150.000 cupos. 
entre el 2002 y el 2007. Para el año 2002 había 77 universidades; 94 instituciones universitarias; 53 instituciones tecnológicas y 43 instituciones técnico profesionales. Para el 2008, había 77 universidades; 100 Instituciones Universitarias; 53 Tecnológicas y 45 Técnico-profesionales. Al tomar el comportamiento de la matrícula según el tipo o carácter de las instituciones, se observa que, para el caso colombiano, ha sido una constante histórica que la primera preferencia de quienes acceden al servicio educativo de tercer nivel se ubica en las Instituciones Universitarias y en las Universidades, quedando como segunda opción la ubicación en las instituciones de carácter técnico y tecnológico. Para 2007 la demanda por educación en Instituciones Universitarias era de 934.736. Para las Instituciones Tecnológicas, su matrícula ascendía a 198.839 y para las Técnicas Profesionales a 173.382.

c) Para los efectos de este trabajo es importante tener en cuenta la vinculación entre los tipos de formación que ofrece el sistema y las demandas de los mercados laborales. En este aspecto es interesante observar dos aspectos. De una parte, el número de programas por área de conocimiento, cuya distribución para el 2008 era la siguiente: Agronomía, 87; Bellas Artes, 223; Ciencias de la educación, 538; Ciencias de la Salud, 524; Ciencias Sociales y Humanas 707, Economía, Administración, Contaduría y afines 1.199; Ingeniería, Arquitectura, Urbanismo y afines, 1.156; Matemáticas y Ciencias Naturales, 170; sin clasificar 1.529; para un total de 6.133 programas académicos ofrecidos en el mercado. De esta distribución debe retenerse la concentración de programas en las áreas de Economía, Administración, Contaduría y afines; y, de igual modo, en Ingeniería, Arquitectura, Urbanismo y afines. Esta tendencia se ha mantenido en las últimas tres décadas. A esta situación debe agregarse la concentración de la oferta en las grandes ciudades. De otra parte, si se cruza esta información con la que produce el Observatorio Laboral se encuentra una gran debilidad de la oferta en áreas claves para el desarrollo del país como, por ejemplo, en los campos de de la Agronomía, Veterinaria y afines. Pero, además, existe una incoherencia entre la estructura ocupacional del país y la oferta educativa. En este último aspecto, el gobierno ha hecho un esfuerzo que incide claramente en el aumento de la pertinencia de la oferta educativa. En efecto, ha logrado en el 2008 que 2.047 instituciones de enseñanza media se articulen al SENA; 324 más, con IES y, a su vez, que 2329 estudiantes de media reciban subsidios para articularse con programas técnico-profesionales. Pero la tendencia a graduarse en los campos tradicionales se mantiene. En efecto, entre 2001 y 2008 el mayor número de graduados en la educación superior fue en Economía, Arquitectura y Urbanismo con 369.428; siguiéndole en su orden Ciencias Sociales con 
211.993; Ciencias de la Educación con 130.294; Ciencias Básicas, Agronomía, Veterinaria y afines siguen ocupando los últimos lugares con el 1.6\% y el 1.4\% de graduados. Es decir, 18.391 y 16.791 respectivamente ${ }^{7}$

d) Una dimensión importante de la situación actual del sistema en su dinámica interna, ya que muestra la necesidad de ampliar la base social del sistema, tiene que ver con la tasa de cobertura. En efecto, ésta es un indicador muy importante de tener en cuenta porque muestra la capacidad con la que cuenta el sistema educativo para integrar a la población a determinado nivel. La diferencia entre la tasa de cobertura bruta $^{8} \mathrm{y}$ la tasa de cobertura neta ${ }^{9}$ identifica cuántos de los que están asistiendo a un nivel educativo no tienen la edad que les corresponde, sea porque están retrasados o adelantados. A partir de las Encuestas Continuas de Hogares del DANE, para los años 2002 a 2007 se calcularon las tasas de escolaridad superior bruta y neta con los resultados siguientes (Ver Gráfica 1)

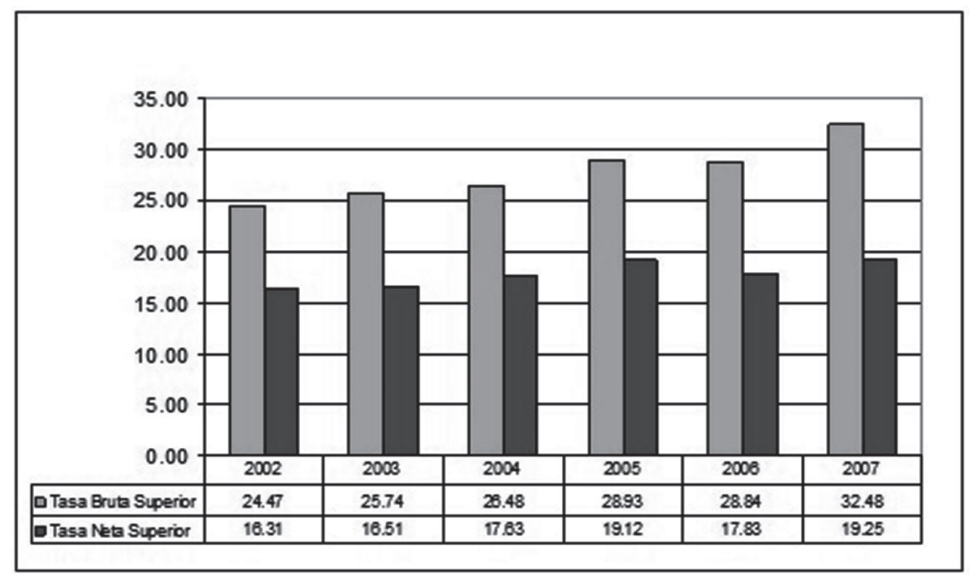

Fuente: Encuestas continuas de hogares, Terceros trimestres 2002-2007. Cálculos propios

$7 \quad$ Queda por estudiar en detalle el aporte del Sena al aumento de cobertura y al proceso de diversificación de la oferta.

8 Tasa de Cobertura Bruta (TCB): Corresponde a la relación porcentual entre los alumnos que asisten a un nivel de enseñanza específico (independiente de la edad que tengan) y la población escolar que tiene la edad apropiada para cursar dicho nivel. La tasa de cobertura bruta se calcula de la siguiente manera: $\mathbf{T C B}$ superior $=$ (Matriculados en educación superior / Población con edades entre 18 y 24 años) x 100. Es factible que en el cálculo de este indicador se obtengan resultados de cobertura mayores a $100 \%$, debido a que toda, o la mayoría de la población en esta edad se encuentra cubierta por el sistema educativo y adicionalmente se encuentran matriculados alumnos en extraedad.

9 Tasa de Cobertura Neta (TCN): Es la relación entre estudiantes matriculados en un nivel educativo que tienen la edad adecuada para cursarlo y el total de la población en el rango de edad apropiado para dicho nivel. Este indicador se calcula de la siguiente manera: TCN superior $=($ Matriculados en educación superior con edades entre 18 y 24 años $/$ Población con edades entre 18 y 24 años) x 100 
La tasa de escolaridad bruta superior para el período 2002 - 2007 varía entre $24.47 \%$ en el 2002 y $32.48 \%$ en el 2007 , lo que significa que para este último año 3.3 de cada 10 personas están asistiendo a la educación superior. El promedio para Latinoamérica, según IESALC es $31 \%$. Colombia estaría por debajo de Bolivia, Cuba, Panamá y Chile.

Mientras que la tasa neta, que da cuenta de las personas que efectivamente asisten al nivel apropiado para la edad, tiene promedio para el período de $17.77 \%$, teniendo una tasa de $16.31 \%$ en el 2002 y $19.25 \%$ en 2007 .

\section{Gráfica 2 - Tasa Bruta de Escolaridad por Quintiles de Ingresso}

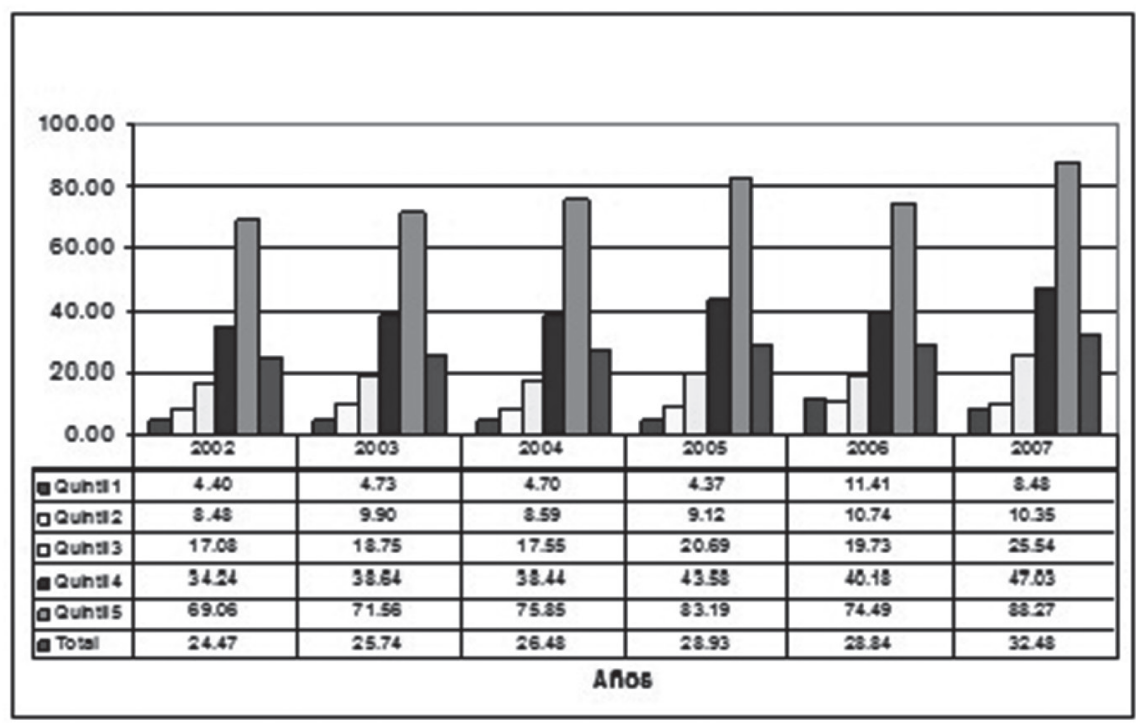

Fuente: Encuestas continuas de hogares, Terceros trimestres 2002-2007. Cálculos propios

Cuando se ven las tasas por quintiles de ingreso las diferencias son amplias: mientras que el quintil uno, el de más bajos ingresos, la tasa de escolaridad superior bruta tiene un promedio de $6.35 \%$ para el período en mención; el quintil cinco, el de mayor ingresos, la tasa promedio sube al 77.07\%. (Gráfica 3)

La tasa de cobertura para el quintil más bajo tan solo se ha incrementado en 4.08 puntos porcentuales ente 2002 y 2007 , mientras que en el quintil 5 el aumento en la tasa ha sido de 19.21 puntos. 
Gráfica 3 - Tasa Neta de Escolaridad Superior por Quinfiles de Ingresso

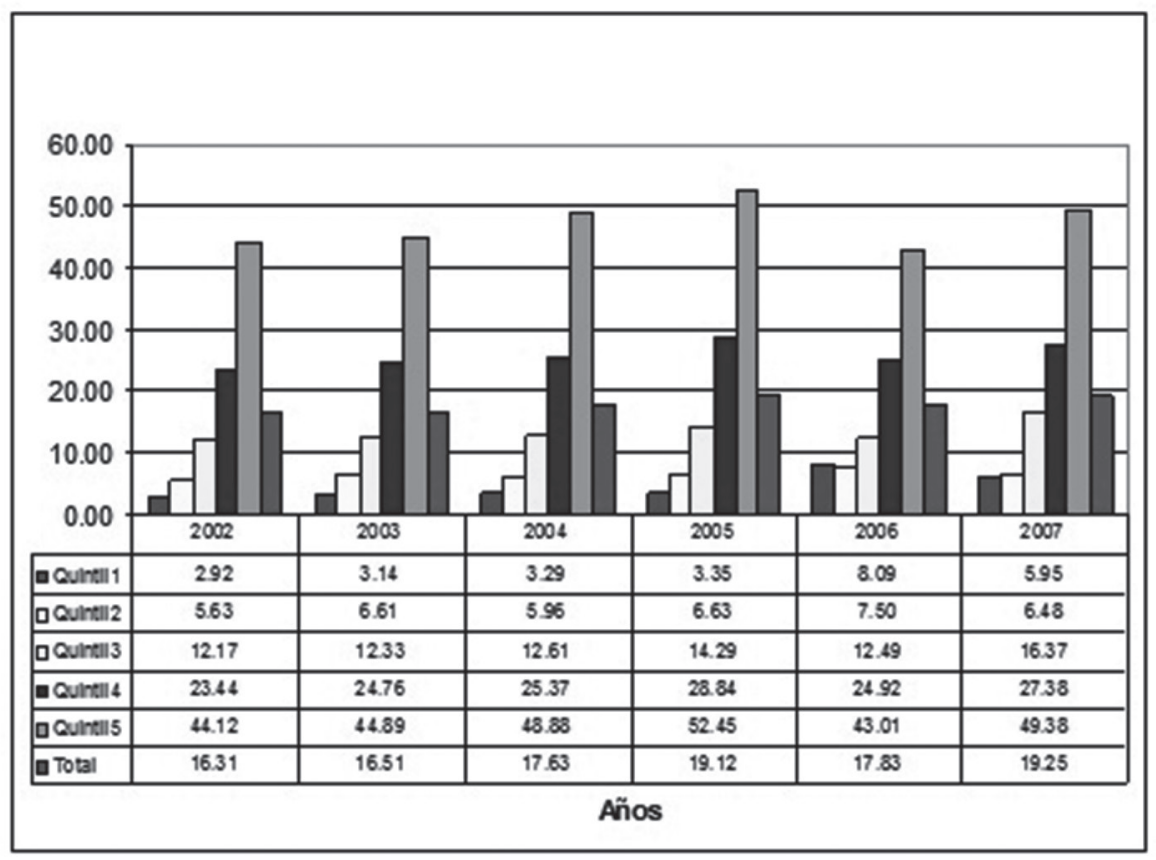

Fuente: Encuestas continuas de hogares, Terceros trimestres 2002-2007. Cálculos propios.

Igualmente, en la tasa neta por quintiles de ingreso, se ven las amplias diferencias entre los niveles de ingreso. Para el año 2007 en el quintil uno, tan solo el $6 \%$ de las personas accede a educación superior, mientras que en el quintil cinco, ese porcentaje sube al $49.4 \%$.

La evolución de la tasa neta por quintiles indica que el aumento para el quintil uno ha sido de 3.03 puntos porcentuales y para el quintil cinco ha sido de 5.26 puntos, para el período de 2002 a 2007.

A partir del análisis anterior vale la pena, entonces, preguntarse por el impacto de la política de cobertura sobre el acceso de los de menores ingresos a la educación superior.

A juzgar por las cifras, a pesar del esfuerzo realizado, el sistema de educación superior permanece siendo inequitativo; lo que refuerza la idea de realizar un viraje en la política procurando poner el acento en la ampliación de base social del sistema. Esta consideración, sin embargo, va más allá del alcance del punto que interesa analizar en este texto. 
e) Finalmente, es necesario llamar la atención sobre el fenómeno de la deserción. De hecho se trata de una de las mayores preocupaciones del gobierno actual. Las cifras muestran que qué tanto el esfuerzo de aumentar cobertura como toda política de calidad se encuentra comprometido con la alta deserción existente.

En la actualidad, en Colombia la tasa de deserción en 2007 es de 46.4\%. Para su estudio, se desarrolló una herramienta informática (SPADIES) que permite hacerle un seguimiento. Este seguimiento pone en evidencia que si bien es cierto que se evidencia un mayor crecimiento de la composición de la población con menores ingresos a nivel nacional a partir de 2003-2; también lo es que esa mayor población proveniente de ingresos bajos es la que se encuentra más vulnerable a desertar de acuerdo con la variable ingreso. El crecimiento de la composición de la población que ingresa al sistema está ligada a la facilidad de los préstamos del ICETEX y de los bancos. También muestra el estudio de SPADIES que en Colombia hay una tendencia a desertar más los hombres que las mujeres, más los que tienen puntaje menos alto en el examen de Estado y más aquellos estudiantes que provienen de hogares cuyo ingreso se encuentra entre 1 y 5 salarios mínimos. Esta situación puede estar siendo alimentada por la inexistencia de apoyos metodológicos entre la población de alto riesgo de deserción que comprende la matrícula entre primero y quinto semestre.

En su conjunto, todos estos indicadores nos muestran la necesidad de diversificar la oferta; disponer de un sistema más flexible; diferenciar claramente para el usuario los atributos de cada tipo de programas que se ofrecen; cambiar en el imaginario social la naturaleza de cada esquema de formación que ofrecen las instituciones; crear condiciones para el mejoramiento en materia de acceso a una oferta con calidad y continuar el esfuerzo hecho en materia de reducción de las asimetrías del mercado educativo de tercer nivel.

\subsection{Comportamiento de la tipología de las instituciones durante el período de vigencia de la Ley 30 de 1992}

\section{Las modalidades técnica y tecnológica}

Como ya lo señalamos más arriba, otra dimensión del diagnóstico tiene que ver con el tema específico de la tipología de las modalidades y la manera como han funcionado desde la vigencia de la Ley 30 de 1992.

Diversos autores señalan cómo uno de los principales factores que condujeron a los países desarrollados a crear nuevas instituciones de educación superior fue la creciente demanda social por nuevas y mayores oportunidades 
de educación post-secundaria. La fuerza de esta demanda está basada en la importancia de los títulos de nivel superior para el acceso al mercado de trabajo y a rangos mayores de distribución del ingreso, estatus y poder (CLARK, 1989; GÓMEZ, v. 2 n. 2, [s.d.]). Estas nuevas ofertas de formación en el sector nouniversitario contribuyen a una mayor democratización del acceso a la educación superior pues amplían el rango de oportunidades educativas para una población altamente heterogénea en intereses y necesidades educativas y ocupacionales.

En diferentes países existen instituciones no-universitarias de alta calidad académica que permiten la continuación de estudios postsecundarios no universitarios. Estas se han constituido en una forma de educación diferente a la que ofrecen las universidades tradicionales. Tal es el caso de Estados Unidos, Alemania, Francia, Holanda, La India; y en la Región: en Brasil, Argentina, República Dominicana, entre otros ${ }^{10}$ Este éxito indica que la diferenciación institucional no necesariamente es fuente de mayores desigualdades y que, por el contrario, es la deficiente calidad lo que hace que su oferta se convierta en opción educativa de segunda clase, como parece que ha sido en el caso colombiano, según se induce de los indicadores antes mencionados.

Pero en Colombia, los críticos de este proceso de 'diversificación' argumentan que la expansión del sector no-universitario no ha implicado modificaciones en la selectividad socioeconómica y cultural del sector universitario y que bajo una apariencia de democratización se ocultan crecientes desigualdades intelectuales y culturales. Las cifras arriba mencionadas parecen mostrar que ello ocurre de tal manera.

Esta situación, para los expertos, contrasta con una de las características de la sociedad moderna que subraya la importancia social, económica y política del conocimiento científico y tecnológico. De hecho, se habla de una "sociedad del conocimiento" y de un "mercado mundial del conocimiento". En este esenario, la calidad de la educación en estos campos es una condición básica para el desarrollo y una ventaja comparativa entre países, regiones y empresas. De ésta depende la colocación adecuada de los países en el escenario mundial y la posibilidad de que los egresados se ubiquen dignamente en los mercados de trabajo. A su vez, la creación de capacidad de innovación científica y tecnológica requiere la diversificación y especialización de la estructura ocupacional, lo cual tiene importantes efectos sobre una mayor equidad social en la distribución del

10 Jorge Enrique Celis Giraldo (2006) Una mirada a la oferta de programas tecnológicos (pregrado y posgrado en el mundo). Para los casos de América Latina, hemos consultado la legislación de cada país cuidando de tomar la normatividad actualmente vigente. De igual modo, se revisaron los estudios de la OCDE al respecto, en OCDE (2005) Education Policy Analysis. Alternatives to Universities Revisited. 
ingreso, del poder y del estatus, aumentando la legitimidad política de la socie$\mathrm{dad}^{11}$. Dichos cambios en la estructura ocupacional dependen y se alimentan en gran medida del grado de diversificación de la oferta de educación superior. Por lo tanto, debería buscarse disponer de un sistema que siendo diversificado, mantenga la diferencia entre ofertas académicas sin desvalorización entre ellas y aceptando que los diversos esquemas de ofertas pueden tener objetivos y retos comunes pero distintos. Por lo tanto, la naturaleza y las funciones de la universidad no son las mismas que las que tienen otras instituciones que brindan programas en el tercer nivel de la educación del país sin que ello vaya en desmedro de su legitimidad y valor.

A la luz de este planteamiento podemos observar lo que pasa en América Latina en relación con la tipología de instituciones. En la mayoría de los países prima el esquema binario o dual de diversificación que se caracteriza por la separación entre las instituciones universitarias, que constituyen el sector de alto estatus social y académico, y las no- universitarias, que típicamente ofrecen carreras cortas, de formación técnica y tecnológica y de bajo estatus social y académico. Parecería que a tal taxonomía subyace un concepto empobrecido de la tecnología moderna y de su papel en el desarrollo de los países en el marco de una economía globalizada.

Tal es el caso colombiano desde $1980^{12}$ y aún antes, al considerar que el tecnólogo "ocupa una posición intermedia entre el ingeniero titulado por una parte, y el obrero calificado por otra, más cerca del primero que del segundo, poseedor de conocimientos técnicos en un campo especializado y habilidades y destrezas particulares que le permiten actuar como personal auxiliar del ingeniero correspondiente". Al parecer, esta concepción ha contribuido a generar una estratificación vertical y jerárquica entre los diferentes tipos de instituciones, colocando a las universidades de corte tradicional en la parte superior y al resto de instituciones en un menor estatus académico y social, obedeciendo, quizá, más a factores culturales que técnicos.

Pero ¿Cómo sucedieron las cosas en materia de diversificación de la educación superior en Colombia?

11 En esta dirección y propósito se ha manifestado claramente el documento de Planeación Nacional. Colombia 2019

12 Para este trabajo se comparó la legislación de diferentes países, entre ellos: Argentina; Brasil; España; Costa Rica y en todos ellos existe sistema dual; naturalmente, sin que tenga en todos ellos la misma connotación en el imaginario social. Más aún en el caso de Colombia se propuso hacia el 2001 la formación de un "subsistema de educación para el trabajo" conformado por las modalidades denominadas técnica profesional y tecnológica y el SENA que para el momento recibió la autorización para adelantar programas tecnológicos con autonomía propia y sin sometimiento a las exigencias del hoy denominado Registro Calificado. 
a) En las décadas de los sesenta y setenta surgieron diversas modalidades de educación postsecundaria orientadas hacia la formación para el trabajo (LUCIO; SERRANO, 1992) ${ }^{13}$. El Decreto 80 de 1980, en el marco del sistema dual al que hemos hecho referencia, distinguía entre modalidades intermedias profesionales, tecnológicas, universitarias, y avanzada. La primera era entendida como aquella que se ocupa de la formación predominantemente práctica para el ejercicio de actividades auxiliares o instrumentales concretas. El título al que conduce es el de técnico profesional intermedio. La segunda, se ocupa de la educación para el ejercicio de actividades tecnológicas, con énfasis en la práctica y con fundamento en los principios científicos que la sustentan. Conduce al título de tecnólogo en la rama correspondiente. Por su parte, la tercera modalidad o sea la universitaria, se caracteriza por su amplio contenido humanístico y social y por su énfasis en la fundamentación científica. Se orienta hacia el mundo de las profesiones liberales y de las disciplinas. El título que otorgan está asociado al de la disciplina o profesión correspondiente (MEN. Decreto 80 de 1980. Arts. 25-49). La última, es una modalidad que como su nombre lo indica se refiere a la educación de postgrado en el nivel de especialización, maestría o doctorado y tiene como objetivo la formación para el logro de un mejor desempeño profesional y la investigación. Aunque en la práctica no funcionó, el Decreto previó la posibilidad de la transferencia del estudiante de una modalidad a otra; como también la posibilidad de una organización del plan de estudios por ciclos entre todas las modalidades.

En síntesis, a partir del Decreto 80 de 1980, las modalidades eran las siguientes:

- Intermedia profesional, y conducía al título de Técnico profesional intermedio

- Tecnológica, y conducía al título de Tecnólogo

- Universitaria, y conducía al título de profesional

- Avanzada, y conducía al título de especialista, maestría o doctorado.

El problema de estas nuevas modalidades desde 1980 radicó en el bajo estatus social y educativo que se les otorgaba ya que la sociedad privilegiaba y sigue privilegiando la universidad tradicional. Estas nuevas instituciones buscaron la revaloración de su estatus emulando la educación universitaria en vez de orientarse hacia la consolidación de una identidad propia que pudiese haber

13 Estos planteamientos fueron ampliamente discutidos en la conformación del anteproyecto de Ley 30 de 1992, sin haber podido avanzar suficientemente en la materia. 
repercutido en una alta demanda. De esta manera, aún las normas, favorecieron su transformación y paulatinamente fueron avanzando de su status inicial al de Universidad. A su vez, este cambio les permitía gozar de algunas prerrogativas fiscales que estimulaban su transformación. Adicionalmente, la ambigüedad conceptual del Decreto 080 de 1980 respecto a los objetivos y definiciones de cada una de éstas y el hecho de que nunca existió una fuerte demanda por los egresados de estas dos modalidades ni una demanda diferenciada por cada una, contribuyó a crear mayor confusión. Por lo tanto, se presentó una especie de indiferenciación en el mercado de trabajo indicando la mala calidad de la formación ofrecida. A finales de los años ochenta, el problema fue plenamente reconocido y por lo tanto el Instituto de Fomento de la Educación Superior (ICFES) lideró un proceso de discusión sobre el tema y sobre las opciones de posibles políticas en la educación superior (ICFES, 1997; ICFES-ASCUN, 1997). En consecuencia, cada modalidad se volvió un nicho excluyente y desarticulado dentro del "sistema".

b) La Ley 30 de 1992 trató de replantear la tipología y para ello estructuró la primera parte de la Ley construyendo la tipología de las instituciones no sobre modalidades sino sobre lo que denominó "campos de acción de las instituciones". Así se llegó a la siguiente nomenclatura de campos: técnica; tecnología; ciencia; humanidades, arte y filosofía. Y sobre esta base se estableció la tipología ya conocida de instituciones técnico-profesionales, universitarias, o escuelas tecnológicas y universidades; e hizo un esfuerzo por definir desde el punto de vista epistemológico la diferencia entre estos tipos de conocimiento. En el proyecto de Ley presentado al Congreso de la República se definió con cierta claridad el significado y alcance del término "universidad". Pero en la versión aprobada por el Congreso se señaló que Universidad era un término que se aplicaría a las que ya existen más lo señalado en el proyecto de Ley; con lo cual se volvió la no claridad ya existente y, además, se autorizó la transformación de las instituciones y se conservó la denominada educación por ciclos y las transferencias. Aspectos estos últimos que no tuvieron aplicación ${ }^{14}$. A este propósito el texto de la Ley señala:

Art. 17. "Son instituciones técnicas profesionales, aquellas facultadas legalmente para ofrecer programas de formación en ocupaciones de carácter operativo e instrumental y de especializaciones en su re-

14 En el caso de las trasferencias se mantuvo la autonomía de las instituciones para aprobar o no las solicitudes de transferencias según que se considerara que el plan de estudios de solicitante fuere o no semejante o igual al del programa recipiendario. 
spectivo campo de acción, sin perjuicio de aos aspectos humanísticos propios de este nivel".

Art. 18. Son instituciones universitarias o escuelas tecnológicas, aquellas facultadas para adelantar programas de formación en ocupaciones, programas de formación académica en profesiones o disciplinas y programas de especialización"

Art. 19. "Son universidades las reconocidas actualmente como tales y las instituciones que acrediten su desempeño con criterio de universalidad en las siguientes actividades: la investigación científica o tecnológica; la formación académica en profesiones o disciplinas; y la producción, desarrollo y transmisión del conocimiento y de la cultura universal y nacional" (MEN. Ley 30 de 1992).

En consecuencia, a partir de la expedición de la Ley 30 desaparece el concepto de "modalidades" de educación superior técnica profesional y tecnológica; y se plantea que las IES tienen diferentes campos de acción: técnico, tecnológico, científico, humanidades, filosofía y artes. De ahí se deriva el cuestionamiento sobre cómo diferenciar los campos de acción técnico y tecnológico, máxime cuando posteriormente la normatividad otorgó la posibilidad de adelantar programas de profesionalización a las primeras, y de entrar en la formación avanzada a las segundas.

Adicionalmente, las instituciones tecnológicas se introdujeron al sistema por la vía de la Ley 115 de 1994. Art. 213 o Ley General de Educación. "Las actuales instituciones tecnológicas y las que se reconozcan con arreglo a la ley son instituciones de educación superior". A su vez, fueron facultadas legalmente para ofrecer programas de formación en ocupaciones, programas de formación académica en disciplinas y programas de especialización, en sus respectivos campos de acción. .. a los títulos que expidan por los programas ofrecidos se les antepondrá la denominación de "técnico Profesional en ...", si se refiere a ocupaciones. Si hacen relación a disciplinas académicas, al título se le antepondrá la denominación de "Tecnólogo en"... (MEN. Ley 30. Art. 16 ).

A su vez, se generó una confusión entre los programas y disciplinas que los diferentes tipos de instituciones pueden ofrecer. Así por ejemplo, al definir la educación tecnológica como "formación académica en disciplinas" ésta pierde identidad y desaparece pues se substituye por cualquier campo del saber de tipo disciplinario, abandonando el campo tecnológico. Igualmente, incrementa el proceso de la escalera o transformación institucional, mediante el cual estas instituciones tecnológi- 
cas se transforman en universitarias y posteriormente en universidades tradicionales. La distinción entre las modalidades era formal, puesto que no había identidad ni diferencias claras entre ellas.

Al reforzarse de hecho el esquema binario o dualista se acentúa la diferencia entre las universidades tradicionales como cúpulas o élites académicas, que representan el "deber ser" ideal de la educación superior, y los otros tipos de instituciones de este nivel educativo, como las instituciones técnicas y tecnológicas, que se consideran de menor estatus académico y social.

A raíz de la Ley 30 también se ratifica y se refuerza el carácter terminal de las instituciones técnicas, condenándolas a un futuro incierto y sin posibilidades de continuación de estudios superiores para quienes lo quieran o puedan hacerlo. Lo anterior es entonces un despropósito desde una perspectiva económica de la formación de recursos humanos como de la igualdad social de oportunidades educativas.

c) Ahora bien, se acepta, como es opinión general, que la solución para cubrir tal déficit en recursos humanos calificados es una mayor flexibilidad, apertura, complementariedad y continuidad en las oportunidades de formación para no limitar las oportunidades institucionales y personales para crecer en el conocimiento. En esta dirección se ha orientado la política pública del gobierno actual pero sin replantear el concepto de educación tecnológica, buscando su consolidación y ampliación a través de la Ley 749. Esta última bajo la denominación de ciclos propedéuticos busca articular mejor el sistema de educación superior, hacerlo más flexible, y propiciar las transferencias de una modalidad a otra. También quiso trascender el carácter terminal de la modalidad tecnológica y ofrecer la profesionalización en los campos de las ingenierías, la administración y las tecnologías de la información; sin que haya logrado quitarle a la misma su carácter intermedio de la modalidad técnica a la profesional en los campos mencionados (MEN. Ley 749 de 2002). Pero la Ley adolece de claridad conceptual en su fundamento, aunque buscó responder a la urgencia de disponer de una oferta educativa apropiada para la diversidad de la demanda existente. Demanda más diferenciada hoy que ayer y que busca formación técnica y tecnológica de calidad ${ }^{15}$. En la forma en que

15 Es fundamental para el inmediato futuro que el país disponga de una oferta pública de educación técnica y tecnológica que atienda las nuevas demandas. En esta perspectiva deberían buscarse caminos audaces de articulación entre el nivel previo al universitario y la educación superior. 
lo prevé la Ley, lo propedéutico se vuelve una imposibilidad práctica y un principio formal de articulación entre ciclos que no va más allá de la representación gráfica siguiente:

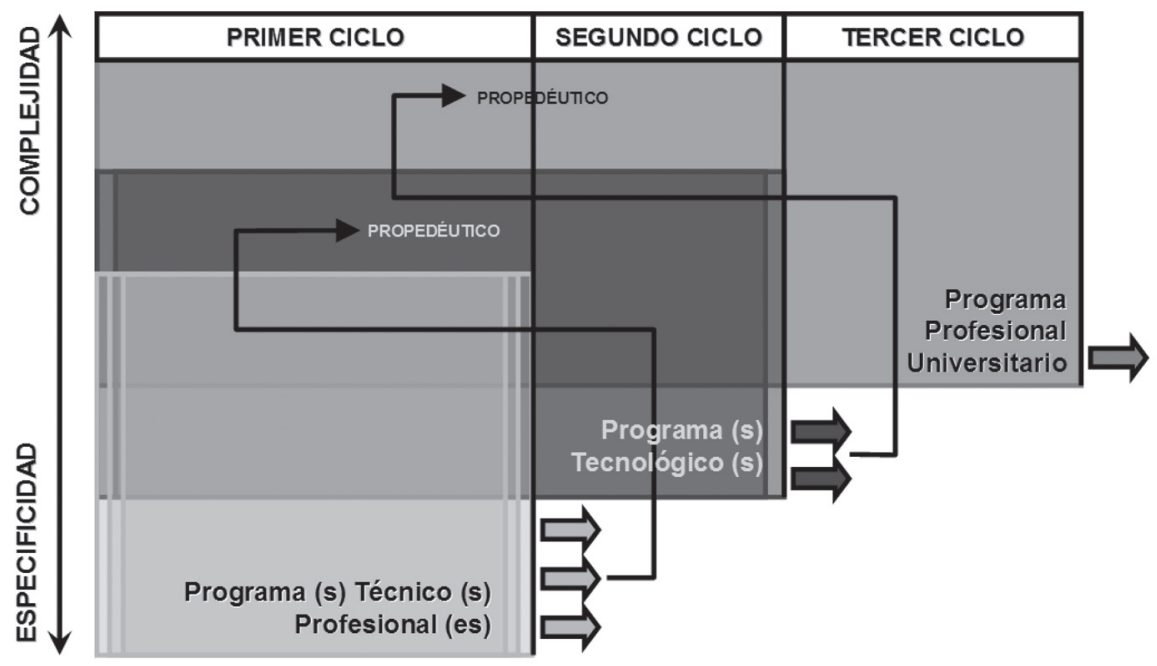

Información MEN. Formación por ciclos propedéuticos

Ahora bien, si se compara la propuesta de la norma en el sentido de que el ciclo técnico sea propedéutico respecto de un segundo ciclo tecnológico; y que éste lo sea igualmente, respecto al ciclo profesional; en la medida en que en la práctica el primero es absolutamente insuficiente para lograr la formación sólida en materia de ciencia básica que requiere el segundo y en cadena el segundo tampoco lo logra respecto del ciclo profesional, lo que queda claro es que en la práctica no se ha podido darle a la formación tecnológica la identidad que requiere y la calidad pertinente en los programas que de hecho se han ofrecido y ofrecen en la actualidad. A pesar del esfuerzo de la norma 749 de 1992 la formación tecnológica sigue siendo un puente hacia la ingeniería.

En el contexto organizativo actual de la educación superior en el país, como lo señala Víctor Manuel Gómez, con quien nos identificamos en los planteamientos hechos en este acápite, todos pierden porque: a- se reduce el grado de diversificación de la oferta y por la misma razón el número de oportunidades para la expansión del sistema; b- muchos campos ocupacionales exigidos en el campo laboral (de carácter tecnológico) permanecen sin ser atendidos en los 
formatos de educación ; c- la Identidad de las instituciones técnico-profesionales y tecnológicas se diluye y su distinción para los empleadores es inexistente; del concepto de universidad se diluye en una conglomerado de instituciones que en la práctica poseen una oferta educativa similar, a saber: formación técnica, más especializaciones; formación tecnológica para profesiones y disciplinas; formación universitaria que se ocupa tanto de la formación tecnológica y disciplinaria para profesiones y disciplinas.

La conclusión a la que se llega, al revisar los estudios existentes y las condiciones internas de operación de la modalidad técnico-profesional y tecnológica, es que en la actualidad la situación dada desde principios de los ochenta se ha reforzado. En efecto, estas modalidades educativas no constituyen una alternativa a la educación superior tradicional, pues gozan de bajo estatus social y académico. Tampoco han tenido influencia significativa en la modificación de los patrones tradicionales de la concentración de la demanda en áreas de saber e instituciones. Más bien, se caracterizan por tener una escasa cobertura en la educación superior y por las limitaciones que tienen, a pesar de los esfuerzos hechos y con reconocidas excepciones, para ofrecer una educación de calidad y nivel que se requiere para la modernización del país. La razones que aducía Víctor Manuel Gómez, parece que aún se conservan y son las siguientes:

- Poseen una tradición intelectual que no tiene nada que ver con la técnica y la tecnología modernas.

- En la mayoría de los casos, con contadas excepciones, se han especializado en formación para oficios u ocupaciones de bajo nivel de calificación.

- Con demasiada frecuencia los programas académicos que ofrecen adolecen de bases científicas, humanísticas y metodológicas.

- $\quad$ No parece que a mediano plazo, puedan suplir las carencias pues necesita invertir en personal docente altamente calificado y en la organización de centros de investigación. De hecho, como se mostró más arriba, su participación en el Sistema de Acreditación de alta calidad es relativamente bajo.

- El mercado que atienden proviene de un creciente número de jóvenes egresados del nivel medio que aspiran a educación superior. Sin embargo, la mayor parte de su matrícula corresponde a bajos puntajes en el ICFES. 
Adicionalmente, con base en la experiencia de CONACES, podemos afirmar que algunas de estas instituciones no cuentan con la infraestructura física y pedagógica mínima, ni con personal docente con producción intelectual demostrable (GÓMEZ, [s.d.]).

La principal función de estas instituciones ha consistido en desviar la alta demanda por educación superior. Por otra parte, sólo muy pocas universidades públicas han integrado la educación técnica y tecnológica en sus ofertas de formación, en parte por la subvaloración de este tipo de educación y por el concepto de que la educación tecnológica es una modalidad terminal.

Por lo tanto, es necesario diseñar estrategias de fortalecimiento académico de estas instituciones ya que por sí mismas no pueden lograr altos niveles académicos. En esta dirección, la norma debe precisar su identidad y el alcance y límites de sus funciones de modo diferenciado. Por lo tanto, este análisis conduce a sugerir, de igual modo, una revisión de la Ley 749 .

El objetivo primordial de la educación tecnológica debe ser la generación de una capacidad de investigación y desarrollo que permita la creación de nuevas tecnologías para contribuir eficaz y creativamente a la modernización y competitividad internacional del sistema productivo nacional. La educación tecnológica moderna de alto nivel académico debe estar estrechamente relacionada con el nivel universitario, principalmente con las ingenierías y con las ciencias aplicadas, más no de manera exclusiva y excluyente, pues debe estar sólidamente fundamentada en los conocimientos científicos relacionados con la tecnología objeto de estudio; independientemente de que se articule o no con alguna ingeniería en particular Así, se lograría asegurar su fundamentación científica y metodológica y darle estatus académico y social (GÓMEZ, [s.d.]; CELIS, 2006) y no seguir considerándola, sin más, como un ciclo de las ingenierías.

Como consecuencia, habría que señalar que aún después de la Ley 30, 17 años después la situación es la misma que ACIET y ACICAPI reconocieron en su autoevaluación de 1996, cuando hablaban de

el atraso e insuficiencia de la dotación e infraestructura técnica y pedagógica; la escasa vinculación con el sector productivo; la ausencia de comunicación e interacción con las instituciones académicas de investigación y desarrollo tecnológico; [...] la concentración de la oferta en pocos programas tradicionales (principalmente Administración y Contaduría) que poco tienen que ver con la tecnología (ICFES-ASCUN, 1997, p. 11). 
Una alternativa de organización de la educación superior requiere entonces diferenciar horizontalmente diversos subsistemas o instituciones según sus diferentes objetivos y funciones (diferenciación funcional horizontal). Una diversificación de oportunidades educativas necesita entonces ser equivalente tanto en calidad como en estatus educativo entre los tipos de institución para poder ser verdaderas alternativas a la educación académica y contribuir al mejoramiento del acceso. Esta podría ser una alternativa pertinente en el caso colombiano. Para ello, es necesario replantear la tipología actual de las instituciones que consagra la Ley 30 de 1992 sin centrar la organización de las instituciones con base en los campos de acción sino en las características de su oferta educativa.

En este contexto, la educación tecnológica puede ser reorganizada como el primer ciclo de la formación en Ingenierías o en otros campos científicos y en algunas áreas importantes de aplicación de las Ciencias, con carácter independiente; o en forma independiente. Este ciclo tendría las mismas o análogas bases científicas y teóricas que las Ingenierías o Ciencias Aplicadas pero se diferenciaría en su orientación de carácter aplicado e incluiría experiencia práctica en la producción. El título otorgado sería el de tecnólogo. El segundo ciclo tendría otros dos años de duración, otorgaría el título de ingeniero profesional o su equivalente internacional y estaría enfocado a una formación de mayor nivel científico y teórico. El primer ciclo no es ni automática ni necesariamente propedéutico para el segundo, aunque debe proveer las bases teóricas y metodológicas para éste ${ }^{16}$. Si hoy no disponemos de una oferta adecuada en estas modalidades no significa que no se pueda tener hacia el futuro, hasta el punto de que las instituciones que de ellas se ocupan puedan brindar niveles superiores de formación y de titulación, como ocurre actualmente en otros países ${ }^{17}$.

Esta organización por ciclos puede significar una innovación en la formación tradicional del ingeniero colombiano, comúnmente considerada como excesivamente teórica y que no conduce a la creatividad tecnológica. Así mismo puede representar una alternativa para el alto número de estudiantes que deben abandonar sus estudios por razones económicas o académicas o por insatisfacción con la forma tradicional de formación. Lo anterior reduciría las altas tasas de deserción estudiantil y aumentaría la eficiencia interna de las facultades de ingeniería y contribuiría a la vinculación orgánica entre educación y trabajo a lo largo de la vida. Se tratará, entonces, de buscar una posición adecuada de la

16 Sobre flexibilidad, educación por ciclos y política de créditos, los miembros de la Sala de coordinadores de CONACES y la Sala Institucional han adelantado reflexiones que el autor ha recogido en este Documento.

17 Queda por estudiar de modo pausado el caso de la formación que otorgan en la actualidad las denominadas instituciones universitarias. 
educación tecnológica sin reducirla a ser un punto intermedio entre el técnico $\mathrm{y}$ el ingeniero.

La formación por ciclos le permite al estudiante progresar en el tiempo en su formación según sus intereses y capacidades de manera continua y permanente. Ello es exigido hoy en día por factores demográficos y por cambios en la naturaleza del trabajo y del conocimiento en la sociedad moderna. Se trata de importantes tendencias en el mundo laboral. Por consiguiente, no es posible educar por un momento sino para toda la vida productiva del individuo para lograr la adaptabilidad ocupacional y la autonomía. Al aceptar la necesidad y conveniencia de un sistema de ciclos no necesariamente propedéuticos, es necesaria la definición y normalización del conjunto de competencias básicas mínimas requeridas para los estudiantes del primer ciclo, para que sea posible la equivalencia académica de programas, la transferencia nacional entre instituciones y la capacidad del estudiante para continuar sus estudios según sus intereses y capacidades.

La organización de la enseñanza por "ciclos" impulsaría reformas curriculares en diversos programas universitarios, en áreas profesionales y aún científicas. Estas reformas tendrían ventajas como la posibilidad de ofrecer alternativas más cortas y de nivel profesional, lo que aumentaría el número de personas calificadas, estimularía la innovación en la enseñanza de programas considerados demasiado teóricos y permitiría “desacralizar" los modelos tradicionales de formación universitaria larga y estimular la innovación pedagógica, curricular e institucional.

Este tipo de formación se adquiere tanto en las universidades sin desmedro de que también se alcance en instituciones de carácter estrictamente tecnológico ${ }^{18}$.

De esta manera, un "Sistema" de educación superior puede estar formado por diversos tipos de instituciones definidas a partir de la oferta que tienen. Lo que define al "sistema" no es el lugar donde se adquiere la formación sino el tipo de programas que se siguen. En consecuencia, es a partir de las características de la oferta desde donde podría organizarse el Sistema de Educación Superior en el país.

\subsection{La modalidad universitaria. Nuevos escenarios y nuevos retos}

El caso de la modalidad universitaria durante los últimos 17 años de la vigencia de la Ley 30 de 1992 es diferente al de las otras modalidades. Más

18 Esta es la conclusión a que se llega después de analizar la experiencia internacional en materia de ecuación de tercer nivel. 
allá de los avatares jurídicos y de juegos de poder, ha habido cambios sustantivos tanto al interior de la dinámica del sistema (en sus formas de operación en virtud de nuevas normas y en la manera como éstas se han interpretado) como en el sector externo. En este último, se han dado cambios de la mayor importancia asociados a las exigencias derivadas de la globalización; de las nuevas formas de producción y reproducción del conocimiento; de la importancia del conocimiento en la generación de riqueza; de la evolución de los mercados laborales; del impacto sobre la educación superior del acceso masivo a la información disponible en las redes operativas de información a través de INTERNET y las WWW y de la incorporación de las nuevas tecnologías en docencia, administración y organización de las actividades de investigación. Todos estos tópicos han generado "turbulencias" en el sistema educativo de tercer nivel y han colocado a las IES ante nuevos escenarios tratando de reaccionar de modo adecuado en una especie de "vértigo de adaptación"19.

De otra parte, el potencial educativo de nuevas Tic's, la necesidad de la innovación, de aumentar la flexibilidad y diversificar la oferta educativa, de incrementar su pertinencia y disminuir la deserción; pero, sobre todo, la necesidad creciente de ampliar la base social del sistema, exige nuevos y diferenciados retos según los distintos tipos de instituciones. En este nuevo escenario, la intervención del Estado, vía la adecuación de las normas, puede ser un factor que contribuya positivamente a las distintas instituciones a cumplir con las expectativas sociales respecto de sus nuevas funciones.

La conclusión a que se llega es que los cambios no afectan de la misma manera a todos las instituciones del sistema.

Las universidades, además, se enfrentan a nuevas exigencias en el marco de los sistemas de acreditación nacional e internacional que hace que tengan que ajustar sus prácticas a estándares internacionales no previstos en la legislación de los años 90. De otra parte, estas instituciones se encuentran ante nuevos retos provenientes del cambio de escenario en que se encuentran insertas. A su vez, han dejado de ser el lugar privilegiado de la investigación básica y aplicada; los laboratorios ubicados en las firmas industriales o el establecimiento de centros de investigación, tanto en el sector público como el privado y por fuera del campus crean contextos de competitividad para la "investigación académica" más inclinada hacia la producción del cono-

19 La literatura sobre los retos de las instituciones de educación superior es muy amplia. Véase: B. Clark. (1997), J-J.Brunner (2001), Orozco Silva (2001a), Global University Network for Innovation (2009), J-J. Brunner y Otros (2007), UNESCO (2007). 
cimiento que hacia su aprovechamiento creativo en un sistema distribuido de investigación aplicada, tecnología, transferencia tecnológica, con grandes virtualidades. ${ }^{20}$

Más aún, se señala con cierta fuerza en el debate internacional que para que la universidad pueda mantenerse competitiva tendría que formar cuadros de trabajadores del conocimiento o "analistas simbólicos", personas que hacen de intermediarios, identifican y resuelven problemas valiéndose de símbolos. Son personas que simplifican la realidad con imágenes abstractas que se pueden reordenar, alterar y experimentar con ellas, comunicarlas a otros especialistas y, finalmente, convertirlas nuevamente en una realidad. Para ello utilizan instrumentos de análisis, obtenidos a través de la experiencia. Los instrumentos pueden ser algoritmos matemáticos, argumentos legales, tácticas financieras, principios científicos, observaciones psicológicas acerca de cómo persuadir o entretener, métodos inductivos o deductivos, o cualquier otro tipo de técnica para resolver problemas" (REICH, 1993, p. 177) lo que exigiría a las universidades una reorientación de sus políticas de gestión académica e investigación.

El cuestionamiento llega hasta pensar que el modelo de universidad tradicional o clásico está agotándose haciéndose necesario una especie de re-fundación de las universidades (REICH, 1993) que traería consigo un replanteamiento de sus funciones tradicionales. Frente a este modelo surge el denominado "modelo pragmático" centrado en las demandas de los mercados, en la investigación aplicada y en la función de capacitación para el trabajo bajo la presión de las fuerzas del mercado.

No es necesario ver una oposición abierta entre el denominado modelo tradicional o "reflexivo" de universidad y un modelo "pragmático". Es posible que ninguna institución haya llevado a la práctica, o se encuentre de modo preciso en uno de ellos; ciertamente, se trata de caracterizaciones útiles para percibir algunas tendencias en la forma como operan las instituciones, aún de modo no manifiesto. En todos los casos, se trataría de que las universidades asuman las responsabilidades comunes pero diferenciadas que tienen y que otras instituciones asuman otras tareas igualmente importantes para el desarrollo del sistema como un todo.

20 Este tema ha sido discutido en varias ocasiones en el país. Quizá la última se adelantó después de la Movilización Nacional por la Educación Superior, en el 2001. En ese momento se constituyó una Comisión de expertos que realizó una propuesta en relación con el ordenamiento del Sistema y en su seno se discutió ampliamente el tema. Las ideas que siguen de alguna manera están influenciadas por tales antecedentes porque el autor perteneció a la misma y fue redactor de los puntos de acuerdo generalizados de entonces. 
Si bien, el primer modelo (reflexivo) se inspira en la visión de los clásicos del pensamiento universitario (FICHTE, SCHELLING, JASPERS, NEWMAN; ORTEGA; GASSET, entre otros) asumiendo del presente la urgencia de incrementar pertinencia, calidad y apoyo a las urgencias del desarrollo del país; el segundo se basa en teorías de las Ciencias Sociales sobre el servicio educativo, para subrayar la función económica de éste respecto del crecimiento económico de la sociedad ${ }^{21}$. En esta segunda perspectiva la pertinencia de las instituciones de educación superior y, particularmente, de la universidad se mediría por su contribución al desarrollo de la ciencia aplicada, a la economía nacional y al mejoramiento de las condiciones de vida de los ciudadanos ${ }^{22}$. Pareciera, según algunos, que la Idea de Universidad se ha diluido. El rostro propio de cada institución se definiría desde su carta misional y su oferta educativa y de ello rendiría cuenta.

Más que una opción excluyente el desafío tiene que ver con el difícil equilibrio entre los dos modelos y el imperativo práctico de mantenerse fiel a la "idea" y articulado a los problemas cruciales de la sociedad actual. En todos los casos, se trata de interpretar, entre otros, tres fenómenos que afectan al sistema de educación superior en el país: la necesidad de diversificar la oferta educativa en el marco de una globalización creciente, el papel protagónico que tiene el conocimiento en el proceso de innovación y en general en la sociedad actual, y la creciente demanda por "analistas simbólicos" en el marco de la competencia internacional. Fenómeno, éste último, que se une a la creciente conciencia por parte de la industria, de la investigación básica. El sector externo comienza a mirar a la universidad y otras instituciones de educación superior y tiene expectativas frente a ellas que no existían antes y que parecen no coincidir, en todos los casos, con la manera como las instituciones conciben su propio quehacer y la forma de vincularse a la sociedad. La tensión entre los modelos es grande y así puede apreciarse cuando se evalúa el impacto que puede tener sobre el modelo reflexivo la puesta en marcha de un modelo pragmático ${ }^{23}$.

21 Este aspecto lo he desarrollado en otros escritos, Véase: Orozco Silva y Otros (1989).

22 Véase la discusión sobre el modelo pragmático en Gibbons Michel (1997).

23 A pesar de las limitaciones y riesgos que tiene acudir a taxonomías bipolares para apreciar procesos y realidades complejas, trataremos de caracterizar estos modelos en la forma siguiente:

En el modelo reflexivo:

- Los problemas se plantean y solucionan en un contexto regido por los intereses académicos de una comunidad científica. El contexto se define según criterios cognitivos y sociales que orientan a dicha comunidad y "per se" no exige obedecer a objetivos prácticos.

- La estructura de cada disciplina define lo que cuenta como "buena ciencia" y fija las reglas de juego para quien quiera convertirse en científico. Tanto en la docencia como en la investigación, los criterios de las disciplinas orientan la acción. Tiene una organización jerárquica y tiende a conservar su forma.

- Es, o puede soportar, hasta cierto punto, cierto grado de irresponsabilidad, en el sentido de tener menor preocupación por demandas sociales específicas 
Como lo señalamos líneas arriba, se trata de características muy generales, frecuentemente identificadas por la literatura sobre el tema. Pero aunque así sea, permiten formarnos un esquema, en el caso del modelo pragmático, del tipo de prácticas que está tomando forma en las organizaciones más emprendedoras. Por ello, debemos precisar como idea fuerza, que quizá no se trata de privilegiar uno u otro modelo sino de aceptar el reto de pensar cada uno en su especificidad y sopesar las bondades de cada uno de ellos para definir el futuro inmediato de nuestras instituciones.

Es posible que este vaivén entre modelos se mantenga, entre otras, porque la dirección de las instituciones, especialmente las universidades se orienta de manera prevalente por las iniciativas del poder académico, o de una élite profesional que ejerce el control sobre las orientaciones académicas. Elite formada, en la mayoría de los casos en el modelo reflexivo. Esta situación conduce, a pesar de querer dar respuesta de modo proactivo a las nuevas demandas, a incentivar de hecho el modelo clásico y a privilegiar la "formación universitaria" como la deseable, a pesar de la diversificación existente entre modalidades de formación.

Pero independientemente de esta dirección de la gestión, cuya suerte se juega en el interior de las instituciones, que puede tener otras variables intervinientes que la expliquen y cuyo cambio implica una toma de conciencia de la crisis por la que pasan las disciplinas, las carreras y las profesiones, debemos ir más allá para tomar conciencia de los retos más inmediatos que tiene la educación superior en el país, a saber:

- Con frecuencia, no posee un control colegiado de sus productos.

- Su valor primordial está en la búsqueda del conocimiento en sí mismo.

En el modelo pragmático:

- Se privilegia el "contexto de aplicación". Se trata de una posición contraria a la "búsqueda del conocimiento en sí". Se pregunta si todo lo investigable es viable financieramente. Urge al investigador por la utilidad del resultado. Incluye una negociación permanente con los interesados. El conocimiento tiende a difundirse ampliamente.

- Posee cada vez más un carácter inter- y transdiciplinario. Uno y otro carácter tienen como condición de posibilidad la apertura y flexibilidad teórico-metodológica de las disciplinas particulares para dejarse interrogar en estos niveles entre sí y para construir un discurso que, una vez alcanzado, no es propiedad de ninguna en particular. Tal es el caso de "teorizaciones" sobre medio ambiente, desarrollo humano sostenible, mente y cerebro, entre otros.

- Se caracteriza por tener estructuras de organización que son horizontales, flexibles, transitorias, abiertas a recombinaciones temporales. No tiene un órgano central de dirección. Los puntos de producción del conocimiento pueden ser o no múltiples.

- Al estar los equipos conformados por personas provenientes de campos diferentes, se abren las posibilidades para el surgimiento de nuevos temas y para uso múltiple de los resultados; pero también para adelantar discusiones sobre los intereses de la ciencia y de la investigación, sobre sus valores e ideologías. Es decir sobre la dimensión ético-política del conocimiento.

- En general, posee un sistema de control de calidad muy amplio, en el que los pares juegan un papel preponderante. Se privilegia, igualmente, el criterio de la competencia versus la posesión de un título particular; se miran más cosas que las que implica la preocupación excluyente por el conocimiento en sí.

- Finalmente, se trata de un modelo que obliga a acudir frecuentemente a alianzas estratégicas en el terreno académico y en el de la administración, entre los agentes comprometidos. 
- Mantener viva la preocupación por la calidad y pertinencia del servicio público de la educación en todos sus niveles, introduciendo mecanismos de autorregulación en el quehacer de las instituciones.

- Promover la construcción de un modelo pluralista de intervención del Estado en materia de educación que le permita a aquélla asumir la autonomía con responsabilidad y al Estado ser eficiente en la función de fomento y supervisión de la educación (inspección, control y vigilancia). Esta actitud conlleva la urgencia de repensar el componente institucional del sistema (los organismos coordinadores de la acción del Estado) y desarrollar más ampliamente el carácter público de las instituciones.

- Lo anterior significa que tanto el sector público como el privado de la educación superior haga efectivo su compromiso ético que implica ser lo que deben ser en conformidad con su "idea", cumplir la Ley, y responder a las expectativas sociales respecto de sus formas de operación. Una consecuencia de lo anterior tiene que ver con el rendimiento de cuentas y con las exigencias que se desprenden del carácter de servicio público que tiene el trabajo de las instituciones. Este es quizá uno de los aspectos críticos en la situación actual en la medida en que se presentan dos acentos diferentes y hasta contrapuestos de la naturaleza y alcance de la autonomía de las Universidades. De una parte, hay quienes acentúan el carácter incondicional de la misma, afirmándola como nota sustantiva del concepto de Universidad, muy afín al ideario alemán de Universidad. De otra parte, quienes el énfasis lo colocan en la naturaleza de servicio público que tiene la educación superior y por lo tanto la responsabilidad que de ello se desprende para el ejercicio de las funciones universitarias. Quizá, debe reconocerse que la tensión entre estas posiciones expresa el difícil equilibrio entre lo público de la universidad y lo autonomía sin condiciones que requiere una de sus funciones claves, la producción intelectual. Pero las funciones de la Universidad de hoy deben ejercerse en el marco de la Constitución y la Ley y con conciencia de la responsabilidad que se desprende del reconocimiento que hace el Estado y la sociedad de una institución autónomamente responsable. El Estado debe intervenir para arreglar los desequilibrios, garantizar la fe pública depositada en la Universidad y velar por la cantidad y calidad del servicio que prestan a la 


\section{sociedad ${ }^{24}$ y las Universidades, quizá, podrían acentuar más su carácter} de públicas que el de Estatales en función del servicio que prestan y no, de modo exclusivo, por el origen de los recursos.

- Facilitar el acceso al sistema de educación a los estratos de menores ingresos

- Aumentar la efectividad y equidad del sistema en todos sus niveles.

- Procurar el compromiso de todos los sectores de la sociedad con la dinámica interna de las instituciones que brindan el servicio público de la educación.

Las iniciativas incluyen la posibilidad de que las universidades centradas en la investigación (Universidades de investigación) disminuyan su interés por la docencia orientada a la formación de profesionales; cosa que podrían hacer otras instituciones, de carácter tecnológico, para centrar su potencial en

24 Un ejemplo de acciones que se adelantan entre el Estado y las Universidades lo constituye el ejercicio que se hizo por parte del Ministerio con especial preocupación por el fenómeno de la corrupoción y con el ánimo de evitarlo o precaverlo a través de la aplicación de un índice de transparencia Nacional (ITN) que muestra el mayor o menor riesgo de corrupción en las IES Públicas. Según el Ministerio de Educación, se trató de medir la probabilidad de ocurrencia de hechos de corrupción en la gestión administrativa, asociados a condiciones institucionales que los favorecen o no. Transparencia por Colombia ha sido la entidad encargada de su construcción y ya se encuentra en la quinta edición. Esta herramienta ha sido pensada para el sector público en general y ya ha sido aplicado a 161 instituciones de las tres ramas del poder público. El ITN, se mide a través de tres Factores: a- Visibilidad y rendición de cuentas de las acciones y decisiones en las entidades; b- Sanciones en el plano fiscal y disciplinario que dan cuenta del control externo de las entidades y los procesos de autorregulación; c- Institucionalidad de procesos y procedimientos clave en la gestión administrativa de las entidades. Para cada uno de éstos factores se tienen los indicadores correspondientes. En el caso del sector educativo fueron analizadas 18 entidades, entre las cuales están el Ministerio, el ICFES, el ICETEX y quince entes universitarios autónomos. El resultado fue el siguiente: con riesgo muy alto el $6 \%$; con riesgo alto el $22 \%$; con riesgo moderado el $22 \%$; con riesgo medio el $8 \%$ y con riesgo bajo, el $6 \%$. Según información dada por el Ministerio, después de un análisis juicioso de las cifras, hay puntos que llaman a la reflexión en materia de mejoramiento y que compartimos: a- En el Factor de Visibilidad se requiere fortalecer en las universidades el acceso a la información, mejorar los mecanismos de rendición de cuentas, los sistemas de quejas y reclamos y la publicación de la contratación; b-El Factor Sanción es el mejor evaluado en las universidades; sin embargo, tiene menor peso en el Índice. En este caso, se hace necesario fortalecer la autorregulación a través de la gestión de las oficinas de control interno disciplinario; y c- En cuanto se refiere al Factor de Institucionalidad, se requiere mejorar la selección por mérito, la gestión del recurso humano y el control interno. Debe señalarse que la contratación de docentes en las instituciones analizadas no se tuvo en cuenta. En el sector privado de la educación superior que abarca en la actualidad el $45 \%$ de la matrícula constituiría un elemento central para mostrar transparencia y mejorar el nivel de información de los usuarios del servicio público de la educación, prestado por la iniciativa privada. Este índice de transparencia podría ser un indicador de calidad que se incorporara en el modelo utilizado por el Consejo Nacional de Acreditación (CNA) para el caso de la acreditación institucional. 
el terreno de los postgrados, el desarrollo de las disciplinas y la investigación básica y aplicada, a través de equipos y en el marco del Sistemas de Ciencia, Tecnología e Innovación de cada país. En esta dirección parece que existe un amplio consenso movido por un triple interés: a- El interés público creciente por la educación superior y por los resultados de su operación; b- La situación de extrema fragilidad y rigidez que tiene actualmente el denominado "Sistema de Educación Superior" y c- La expansión creciente y limitada direccionalidad que posee; todo lo cual obliga a que el Estado, como la sociedad civil y las mismas instituciones busquen una solución a la situación actual.

En consecuencia de lo dicho, es necesario estudiar la posibilidad de tener en el país una Ley Estatutaria de la Educación Superior y dos leyes más: Una de carácter reglamentario orientada a ofrecer las normas a que deben sujetarse las instituciones que no son universidades y que no gozan de la autonomía reconocida en la Carta Política a aquéllas y una segunda Ley de Universidades. $\mathrm{O}$, una sola Ley en la que se delimite en capítulos bien diferenciados el campo propio de las universidades y de las demás formas de educación no universitaria. Se trataría de ajustar la normatividad a las exigencias que se desprenden del uso de la autonomía responsable de aquéllas y de reconocer su especificidad, alcance y limites de su actuar en los nuevos escenarios en que operan. Esta proposición implica replantear la tipología de las instituciones, articulándola con base en la oferta educativa que puede ofrecer cada tipo de institución, de acuerdo a dos criterios: el tipo de conocimiento involucrado en los programas y el nivel de formación.

La categorización de instituciones, bajo el presupuesto de que tienen funciones comunes pero diferenciadas, se fundamenta en una clara definición de su oferta educativa, con la precisión de que cada institución deberá responder, a través de procesos de acreditación, por el nombre que ostenta.

\section{PROPUESTA}

\section{1 Ámbito jurídico de la reforma en relación con la tipología de las instituciones}

\section{Capítulo II \\ Objetivos}

Artículo 6. Son objetivos de la Educación Superior y de sus instituciones... En concordancia con los Arts. 1-4 


\section{Capítulo III}

\section{Campos de Acción y programas académicos}

Artículo 7

En concordancia con Art. 8-17-22-25 y 29

Art. 8 (Campos de acción)

Art. 9 (Los programas de pregrado preparan para el desempeño de colaciones, para el ejercicio de una profesión o disciplina, de naturaleza tecnológica o científica; o en el área de las humanidades, las artes y la filosofía)

Art. 10 (Los programas de postgrado)

Art. 11 (Los programas de especialización)

Art. 12 (Los programas de maestrías)

Art. 13 (Los programas doctorales)

Art. 14 (Requisitos para entrar a los diferentes programas)

Art. 15 (Programas de educación abierta y a distancia)

\section{Capítulo IV}

\section{De las instituciones de Educación Superior}

Art. 16. Son instituciones de educación superior

a- Instituciones técnicas profesionales

b- Instituciones Universitarias, o, Escuelas Tecnológicas

c- Universidades

d- En concordancia con: Ley 115 de 1994. Art. 35 y 213

Art. 17. (Definición de cada tipo de instituciones)

Art. 18. Idem

Art. 19 Idem

Art. 20 (Cambio de personería jurídica de las instituciones en el marco de un proceso de acreditación)

Art. 21 (Autorización para ofrecer programas de maestría y doctorado)

Art. 22 (Autorización para la creación de instituciones)

Art. 23 (Clasificación de las instituciones según origen)

\section{Capítulo V}

De los títulos y los Exámenes de Estado

Art. 24 (Definición del título)

Art. 25 (Títulos que pueden ofrecer las instituciones según su tipo)

Art. 26 (De la nomenclatura de los títulos)

Art. 27 de los Exámenes de Estado 


\section{Capítulo VI}

Autonomía de las instituciones de Educación Superior

\subsection{Elementos para una nueva tipología de las Instituciones de Educación Superior.}

Debemos comenzar por señalar que estos elementos de juicio que se presentan a continuación han sido puestos de relieve en diferentes situaciones. La última de ellas, cuando se conformó la Comisión Nacional constituida por parte del Gobierno, en el 2001. Aquí se recogen algunos aspectos de la discusión de entonces y se sugieren otros nuevos.

\section{Arquitectónica del Sistema de la Educación Superior}

\section{Principios}

- La Educación Superior es un proceso permanente que posibilita el desarrollo de las potencialidades del ser humano de una manera integral, se realiza con posterioridad a la educación media, y tiene por objeto el pleno desarrollo de los alumnos y su formación académica y profesional.

- La educación es un servicio público de naturaleza cultural ofrecido por el Estado y los particulares,

- La educación superior es un factor estratégico para el desarrollo sostenible del país.

- El Sistema de Educación Superior se rige por la Constitución y la Ley, por los referentes universales del conocimiento y por las necesidades de la sociedad.

- La autonomía de las universidades constituye un derecho y una responsabilidad frente al cumplimiento de sus funciones propias.

- Constituye un propósito y un interés central del Estado, de la sociedad global y de las instituciones porque a través de la acción de las IES apropiación de la cultura universal, la preservación de la diversidad natural y cultural, el cuidado del medio ambiente, la educación a lo largo de la vida y la consolidación de las comunidades académicas . 


\section{Finalidad de la Educación Superior}

- Satisfacer la necesidad de profesionalización que requiere el país para el logro de un desarrollo sostenible.

- La creación y comunicación de nuevo conocimiento en todos los campos del conocimiento.

- La generación y transmisión de valores culturales que contribuyan a la consolidación de la identidad cultural.

- Estimular el uso de nuevas tecnologías en los procesos de formación.

- Ser un agente estratégico para el desarrollo humano y para la formación y consolidación de las comunidades académicas y científicas.

\section{Principios en que descansa la tipología de las instituciones}

Se trata de ofrecer un esquema de ordenamiento de las instituciones, o tipología, basado en la naturaleza de los programas que ofrecen y en una articulación sistémica de los tipos institucionales.

\section{a) La idea de sistema}

El ordenamiento de las instituciones en un sistema no es arbitrario. En primer lugar es fundamental que este se haga de modo tal que la idea de sistema sea visible, por lo tanto se trataría de una comprensión del Sistema de la Educación Superior como una totalidad compuesta por diversos componentes cada uno de los cuales cumple una función específica y de este modo contribuyen al bien conjunto (organicidad) y además se trata de una relación entre dichos componentes de manera tal que un cambio en uno de ellos implicaría modificaciones en el todo y viceversa. La concepción en términos de sistema permite pensar identidades y diferencias entre las instituciones, tanto como complementariedades en ellas.

\section{b) Apertura, flexibilidad}

El sistema de educación superior teniendo en mente los alcances y límites del ordenamiento anterior de las instituciones hace visible la posibilidad de una apertura continua del mismo hacia los mercados laborales y dentro del sistema a la interacción entre las instituciones y las diversas experiencias de formación que existen en el país y a la movilidad de los estudiantes entre instituciones. 


\section{c) Educación por ciclos.}

Como se señal+ó más adelante este principio es fundamental en el ordenamiento de las instituciones y en la conformación de los programas académicos para facilitar que el estudiante pueda progresar en su formación según sus intereses y capacidades de manera continua y permanente.

\section{De los programas académicos}

En la conformación de los programas académicos se tendrán en cuenta los criterios siguientes:

- Las funciones comunes pero diferenciadas de cada tipo de instituciones y sus propósitos e intereses centrales.

- Los tipos de conocimiento que vehiculan en la conformación de sus programas académicos

- Los niveles de formación que ofrecen las instituciones

Cada institución en función de su naturaleza conforma su proyecto educativo, originándose así una diferenciación y diversificación de la oferta educativa que permite atender diferentes mercados. De igual manera, se reconoce la diferencia histórica y conceptualmente existente entre las universidades y las demás instituciones que ofreciendo educación superior no tienen tal carácter. El reconocimiento de esta diferencia fundamenta que la Carta Política (Art. 69) haya reconocido la autonomía como atributo esencial de las universidades, no así a las demás instituciones ${ }^{25}$. E igualmente, se asume que las universidades tienen una vocación propia que se identifica por la manera como, al organizarse, formulan su vinculación con los niveles de formación que desea ofrecer, con los saberes en cuya producción y transmisión está interesada y en la manera como asume su vinculación con otros tipos de formación del tercer nivel y con las expectativas sociales sobre ella. Esta triple relación le otorga un "rostro propio" que la normatividad debe acoger. Desde esta orientación resultante, cada universidad define su misión y propósitos y los hace operativos en su plan de desarrollo integral y en sus proyectos estratégicos. La norma legal favorecerá la creación de condiciones que permitan el ejercicio de la autonomía responsable y vinculada a las exigencias que se desprenden de la naturaleza de servicio público que prestan. Por ello se postula que las funciones de las instituciones universitarias no son las mismas de las otras instituciones de educación supe-

25 Sobre la autonomía, se está desarrollando un trabajo específico por parte de la Dra. Patricia Linares. Por esta razón no se desarrolla en este texto. Véase un primer acercamiento al tema en: Patricia Linares (2010). 
rior, aunque tengan propósitos y finalidades comunes en el marco del sistema de educación superior del país como, por ejemplo: satisfacer como sistema las necesidades de profesionalización, cultivar y desarrollar la identidad cultural de la nación y desarrollar conocimiento nuevo básico y aplicado a la solución de los problemas propios.

Entre las universidades, puede darse el caso de que algunas de ellas deseen enfocar su trabajo en el campo tecnológico y con un énfasis específico en la investigación aplicada, como su vocación propia. En este caso se denominarán universidades tecnológicas. Pero debe advertirse que el reconocimiento de la diferencia institucional no conlleva una concepción maniquea entre la ciencia y la tecnología. Por el contrario, se trata, como lo hemos señalado más arriba, de un "continuum" que va desde al abordaje práctico de los problemas y preguntas de investigación hasta la formulación teórica de las soluciones posibles y viceversa. Ni la técnica ni la tecnología son la antesala de la ciencia, ni ésta última una estancia extraña al arte, la reflexión y los saberes comprendidos bajo el rótulo de ciencias sociales o humanas, el arte y la filosofía. Se excluye, igualmente, todo reduccionismo de carácter metodológico o epistemológico ${ }^{26}$.

Las instituciones de educación superior, en conformidad con su vocación propia libremente asumida, podrán ofrecer programas académicos de pregrado y posgrado y en su conformación deben hacer referencia a los tipos de conocimiento y niveles de formación implicados. En lo relacionado con la descripción de los programas de pregrado y postgrado seguirán lo previsto por la Ley 30 de 1992 en sus artículos 9-15. A este respecto es importante subrayar la importancia de vincular la educación media con el nivel superior, buscando su articulación de una parte, con el Sena; y de otra, con las instituciones de educación superior (Técnico y universitario). De igual modo, se mantendrá como un principio de orientación el que los estudiantes puedan hacer transferencias entre las instituciones.

Finalmente, todo el sistema de educación se articulará de manera tal que al término de cada ciclo de formación pueda ingresar al mercado laboral y regresar posteriormente, si lo desea, a continuar su proceso de formación, que habiéndose iniciado en la básica primaria, podrá continuar a lo largo de la vida.

26 En este texto se insinúan las tesis teóricas que subyacen al modelo, sin entrar en un análisis de fondo de las mismas. Para un análisis de las mismas, el Autor remite a otros textos donde aborda esta temática en detalle. Véase: Orozco Silva $(2007 ; 2009)$. Este tema fue ampliamente discutido en el 2001 por la Comisión creada para elaborar una propuesta de reforma de la Ley 30 en esta materia y como resultado de las inquietudes surgidas en la movilización Nacional por la Educación Superior, realizada por el anterior gobierno. Al respecto véase: ICFES (2001). 
Se favorecerá la educación por ciclos, la flexibilidad, la movilidad de estudiantes en el sistema y la educación como una opción a lo largo de la vida que debe reflejarse en la posibilidades que brinde el Sistema de la Educación Superior como un todo; y no, como quizá se ha entendido, como si la oferta fuese la misma en todas y cada una de las instituciones. Finalmente, las Universidades podrán incluir en su oferta programas de naturaleza técnica y tecnológica, si así lo consideraran pertinente y acorde con su naturaleza y propósitos misionales. La gráfica siguiente ilustra la conformación de los programas académicos de las instituciones.

Gráfica 4 - Programas Académicos

\begin{tabular}{|l|l|l|l|l|l|l|}
\hline Nweles Tdo c & Técnico & Tecnológico & Ciencias & Humanidades & Artes & Filosofia \\
\hline Técnico & & & & & & \\
\hline Profesional & & & & & & \\
\hline Avanzado & & & & & & \\
\hline
\end{tabular}

\section{Tipos de conocimiento}

En relación con los tipos de conocimiento, como eje definitorio de la oferta educativa conviene recordar el esfuerzo que se ha hecho en el país y que ocupó de modo especial a la Comisión integrada por el gobierno para proyectar líneas de política después de la Movilización Nacional que tuvo lugar en el 2001. En esta dirección y recogiendo las tesis que entonces fueron ampliamente discutidas y proyectándolas al estado de la discusión en el presente podemos señalar en grandes tesis la caracterización siguiente de los diferentes tipos de saber involucrados en la conformación de la oferta educativa del tercer nivel.

\section{Saber hacer técnico}

Al hablar del saber hacer técnico nos estamos refiriendo a aquellos saberes de naturaleza técnica que, propiciando el desarrollo de la persona, se centran en su capacitación práctica para el desempeño en ocupaciones y oficios. A su vez, procuran a quienes los toman el desarrollo de habilidades, destrezas y tácticas específicas en relación con aquellos, más que las justificaciones de naturaleza teórica o lo principios últimos en que tales habilidades y destrezas puedan descansar. Esto no significa que no puedan poseer un carácter altamente racional sino más bien que descansan sobre la base de la observación comparada de los medios y efectos, a partir de una crítica razonada de las prácticas empíricas. 


\section{Saberes tecnológico y científico}

Para caracterizar los saberes tecnológico y científico, partiremos de un doble reconocimiento que tiene particular vigencia: de una parte, la conciencia de la fragmentación de los saberes y de otra, la desconfianza acerca de toda epistemología de carácter general. Debemos aceptar la dificultad básica de explicitar una "definición única" de cada tipo de conocimiento. Nos movemos en un espectro que puede ir desde las ciencias naturales y exactas, y sociales, a la filosofía, pasando por la tecnología, las humanidades y el Arte. Decir esto permite hacer distinciones entre estos tipos de conocimiento sin que por ello los separemos. Con mucha frecuencia se necesitan y complementan entre sí (LADRIÉRE, 1989); todos ellos forman parte de la cultura. En efecto, en el terreno de las ciencias, tanto en la investigación básica, como en la aplicada se utiliza el método científico para la generación de conocimiento nuevo. Pero mientras en la primera el interés es netamente cognoscitivo (incrementar el conocimiento), en la aplicada el interés se centra en la solución de problemas de interés social. Quizá por esto es difícil planificar la investigación básica; no así la ciencia aplicada. En relación con la ciencia y la tecnología conviene precisar que, con frecuencia, esta última utiliza conocimiento científico existente, agrega conocimiento nuevo orientado a diseñar artefactos o cursos de acción que tengan un valor práctico. En todos los casos, no hay tecnología sin fundamentación científica correspondiente. Pero, a pesar de su íntima relación, guardan entre sí una diferencia de naturaleza, toda vez que el objetivo de la ciencia es el progreso del conocimiento, mientras que la tecnología tiene por finalidad la transformación de la realidad dada.

A un nivel más fundamental, el conocimiento científico se expresa en un lenguaje específico que posee un carácter dinámico y cambiante según las épocas históricas. Comprende tanto el lenguaje de las ciencias naturales y exactas como el de las ciencias sociales y humanas sin que en el punto de partida se postule un monismo metodológico; por el contrario, en el caso de las ciencias de la naturaleza su objeto se nos muestra desde afuera. Para investigar en su campo no es necesario acudir a la tradición cultural, ni a la experiencia del pasado acumulada en el lenguaje. De cierta manera, hay una autonomía del objeto de conocimiento. Cuando en su contexto se habla de experiencia, nos estamos refiriendo al proceso riguroso de experimentación en el cual la totalidad o casi totalidad de las variables están bajo control; su método apela a procedimientos sistemáticos que permiten describir, controlar y predecir el comportamiento de los fenómenos sobre los cuales se trabaja, en virtud del descubrimiento de la legalidad natural que los rige. La ciencia se expresa en procesos de investigación 
que con frecuencia originan nuevos campos de investigación o ciencias en las cuales se opera con modelos de explicación adecuados a la naturaleza de los problemas de que se ocupa el hombre de ciencia, en el marco de paradigmas desde los cuales se legitima y define lo que es relevante para la investigación. La actividad científica no se agota en la actividad propia de las ciencias naturales y exactas. Habrá que mantener viva la distinción entre estas ciencias y las sociales y humanas. Sobre su diferencia existe una amplia discusión, que no es del caso reproducir en este texto, pero sí es fundamental señalar que el núcleo del problema radica en la circunstancia de que en estas últimas el hombre es sujeto-objeto de la ciencia, lo cual determina una diferencia de principio, respecto de las ciencias naturales y exactas. Este hecho significa que en las instituciones de educación superior, las ciencias sociales y humanas deben ser asumidas en su especificidad, sin reduccionismo metodológico alguno.

El quehacer científico se prolonga en una dimensión ético-política insoslayable que se expresa en la vigencia de los paradigmas y que nos conduce a pensar en los espacios de formación y en el ethos de las instituciones formadoras de los hombres de ciencia. Se trata de tener en cuenta la "contaminación" de los valores de la ciencia que determinan, en quienes los asumen, una "visión del mundo" iluminada por la probidad y el respeto a las diferencias, por la predilección del argumento fundado frente a la arbitrariedad y al dogmatismo. En una palabra, por una ética de la inteligencia que orienta la acción.

En este sentido, las instituciones que se ocupan de la formación de una alta inteligencia para la ciencia y la tecnología ejecutan una tarea delegada a ellas por la sociedad y a su efectiva ejecución deben servir; definiendo desde sí mismas las mejores estrategias para lograrlo. Por estas razones, las universidades son consideradas como espacios de formación que acreditan su desempeño en cada nivel y tipo de conocimiento con criterio de universalidad, en el marco de la cultura nacional y universal.

Todas las instituciones que pertenecen al sistema de educación superior poseen análogas preocupaciones y se inspiran en los mismos principios; conservando fidelidad irrestricta a las exigencias que se desprenden del tipo de conocimiento que trasmiten y cultivan. Tales exigencias se constituyen en referentes universales del quehacer de las instituciones de educación superior.

\section{EI saber de las Humanidades y las Artes}

Las Humanidades, en el marco de un proyecto educativo, aluden al conjunto de saberes orientados al perfeccionamiento del espíritu humano. Dado que en 
el hombre no coincide su ser con su deber ser, es susceptible de formación; entendiendo por ésta no sólo el producto de la formación sino el proceso para lograrla (OROZCO SILVA, 2001). De esta manera, los saberes referidos al ser humano contribuyen a que el hombre se entienda a sí mismo en el horizonte de la tradición cultural, de la historia, de la estética y del lenguaje, porque al estudiarlos se percibe a sí mismo como Sujeto-objeto; como experiencia de sí hecha saber en cada una de las disciplinas.

Las Humanidades han sido y son consideradas en la historia de las instituciones de educación superior, como un medio para influir en el carácter y en la personalidad del estudiante, aunque hayan variado las estrategias utilizadas en su instrumentación pedagógica. Las Humanidades han sido parte de la denominada formación general, o básica, o liberal y en tal sentido se centran en el aprendizaje de los principios de las ciencias naturales, de las exactas y en el conocimiento de las bases problemáticas de las ciencias sociales, así como en el conocimiento de las grandes corrientes de pensamiento, de las tradiciones culturales, de los hechos históricos, o en el conocimiento de las culturas nacionales a través del estudio de los idiomas clásicos y modernos.

Cierto es, como se consigna en la historia de las viejas universidades europeas que el ingreso de las humanidades a la institución universitaria ocurre desde aproximadamente 1321, cuando Giovanni de Virgilio fue nombrado actorista por la municipalidad con la tarea de hacer lecturas de "grandes autores" de la antigüedad y también del Dante. Para entonces se trataría de volver a los clásicos para ver en ellos un ideal de hombre al que se buscaría recuperar. Es importante tener en cuenta que aún desde antes ya se percibía al humanista como alguien que podía dialogar con los clásicos. Los estudios humanísticos, desde la perspectiva del origen de la institución universitaria, forman parte de facultad de artes y significaron una innovación en el trivium y quadrivium de la época hasta establecerse firmemente en todos las universidades con gran fuerza y reconocimiento social, y extenderse aún por fuera de éstas. Se trataría de lograr mediante el diálogo liberador con los clásicos que la persona desarrollara un pensamiento lógico, una capacidad de discernimiento moral y estético y habilidades para interactuar en el mundo social y profesional. En tal sentido, los saberes a los que se acude no son utilizados como fin en sí mismos; en tal aproximación no se busca formar un profesional, sino incidir en la conformación de su carácter y personalidad. No se trata de un ornato para el individuo, sino de la posibilidad de que se forme en y a través de un repertorio de ideas y convicciones que le sirvan para dirigir efectivamente su existencia (ORTEGA; GASSET, 1982). 
Pero las humanidades, al decir de M. Kant pueden ser consideradas como una propedéutica de las Artes (KANT, 1989). Estas últimas, sin pretender ofrecer una definición unívoca de su quehacer, se encuentran asociadas a una actividad cuya finalidad es estética o comunicativa en la cual se expresa una visión del mundo y cuyos juicios no son apodícticos como aquellos en los que se expresan las certezas de la ciencia. El arte, cualquiera que sea su manifestación ha tenido una función ritual, mágica, religiosa y social y forma parte muy sustancial de la cultura. En las artes se expresa la capacidad creadora del ser humano y a través de ella expresa sus sentimientos, su manera de vivir y habitar el mundo de la vida; aunque originariamente el vocablo utilizado para designarla haya sido el de "téchne" con una referencia marcada a un "oficio técnico", cercano si no sinónimo de destreza o actividad sujeta a reglas específicas (producción de cosas de modo racional). Con el tiempo ha venido a significar un campo del saber relacionado con lo estético, quedando reducida la expresión "téchne" para designar la actividad productora de artículos de uso. En el arte por el contrario, se trata de la puesta en juego de la capacidad creadora del ser humano. En su producción está en juego la inspiración que hace que el arte en cierto modo no se aprenda; o las cualidades sensibles de la obra que la acerca más al espíritu que un conocimiento racional. En ella se expresa el interior del artista. Esta dimensión subjetiva comprometida en la obra de arte no significa que ella no tenga o pueda tener un alto impacto en la sociedad. Pero quizá en todas las posibles definiciones que se brinden, según la perspectiva desde donde se piense su naturaleza propia, hay en el arte una constante que tiene que ver con el potencial que tiene en todas sus manifestaciones para la formación del espíritu humano y para incrementar en el individuo su posibilidad de crecer en humanidad.

\section{El saber de la Filosofía}

La filosofía surge históricamente como "teoría" y como ciencia primera, como saber científico por excelencia en un momento muy anterior al de la ciencia moderna, como saber universal y de lo universal.

La filosofía surge, en su momento, en una actitud científica (no mítica) del hombre, configurando un saber sobre la totalidad, de orden racional (especulativo) cuyo objetivo es llenar ese vacío entre razón y experiencia y que permita emitir sobre esta última un juicio con sentido, a partir de principios racionales. La filosofía surge, a su vez, como saber crítico. Estos tres caracteres del saber filosófico: Universal, racional y crítico nos muestran, hasta dónde la filosofía, en su origen, fue la primera ciencia y la ciencia primera. 
Sin embargo, esta no es razón suficiente para hacerle un reconocimiento dentro del campo de las ciencias (positivas). Más bien, si consideramos la ciencia como, una realidad multiforme y variada, la filosofía permite crear un espacio de reflexión que, más allá de todo campo particular, nos permite movernos a nivel de los fundamentos de las ciencias para hacer ver su unidad, haciendo explícito aquello que de manera específica se muestra en cada una, a saber: las estructuras mismas de la razón y las articulaciones que ésta guarda con la experiencia individual y colectiva. Esta es justamente la función de la filosofía en la universidad, hacer explícita la unidad del saber subyacente a la multiplicidad de los saberes y a las variadas manifestaciones de la experiencia humana. La filosofía es, pues, más allá de toda comprensión desde una escuela de pensamiento, aquel discurso de la razón, hecho posible cuando reconocemos los límites del entendimiento finito.

Pero a un nivel más fundamental es necesario tratar de identificar la especificidad del saber filosófico frente a los demás saberes, particularmente el de las ciencias. Este esfuerzo permitirá hacer claridad sobre los tipos de conocimiento que compromete el Sistema de educación superior que se propone.

Podemos decir que la filosofía es no sólo un saber racional, universal y crítico (OROZCO SILVA, 1982), sino también que es un saber reflexivo sobre la totalidad de la experiencia humana y aunque no goce del privilegio de poder presuponer sus "objetos" como inmediatamente dados, ni ofrecer por anticipado su "método", posee una legitimidad cuyo fundamento radica en una concepción de la realidad y en una teoría del conocimiento.

Desde estas dos consideraciones es posible entender no sólo la filosofía sino también la empresa de la ciencia. Si bien es cierto que entre una y otra podemos señalar una diferencia significativa, hasta el punto de decir con claridad que la filosofía no es una ciencia (positiva), tampoco podemos evitar reflexionar sobre sus relaciones mutuas. Con frecuencia las divergencias nacen o bien de una especie de imperialismo de los criterios de verdad que pretende aplicar a todos los dominios y a todas las situaciones lo que no es legítimo y fecundo sino en el dominio de lo verificable empíricamente; o bien, de un cuidado exagerado de unidad y síntesis. Se olvida con frecuencia que aunque esta última pretensión pueda ser legítima, no es más que una esperanza, pero no una demostración. Tal pretensión y tal esperanza deben pasar por el reconocimiento de la pluralidad de órdenes del saber.

Por encima de la diferencia entre ciencia (positiva) y filosofía debemos recordar que una y otra corresponden a la búsqueda de un saber racional; una y otra son no sólo un saber de "algo" sino un saber de sí mismas (saber 
crítico), sustitución del saber inmediato (ingenuo) por un saber de lo que es y no puede ser de otra manera, en el caso de la ciencia; y por una reflexión sobre la totalidad de la experiencia humana, en el caso de la filosofía, sin que tal búsqueda excluya su articulación con la práctica social global, en relaciones que materializan valores, intereses, ideologías, etc.

Tenemos pues diferentes campos del saber, cuyo nivel de cientificidad no se mide por el paradigma de uno de ellos sino desde el interior de los saberes, en la búsqueda continua de delimitación precisa de objetos de estudio, de métodos pertinentes y de conceptos exactos.

La "cientificidad" representa una idea regulativa y no un modelo determinado elaborado de una vez para siempre. La historia de esta "idea" nos muestra que la concepción dominante en un momento dado, no es un "a priori" que desde el exterior de la dinámica científica defina normativamente lo que es o "debe ser" lo científico. La Obra de Khun, como los trabajos de Edgar Morin, nos presentan la imagen de la ciencia como algo que evoluciona mediante la alternancia de paradigmas y con la mediación de crisis y revoluciones entre ellos, las cuales van determinando configuraciones diferentes del saber e "ideas" de la ciencia en continua lucha (KHUN, 1985; BARNES, 1980; HABERMAS, 1973; HORKHEIMER, 1974; Morin, 1992; GIDDENS, 2003; OROZCO SILVA, 2006; MOUFFE, 1996).

La cientificidad toma forma en una actitud y una práctica metódica que como empresa cognoscitiva se da en el pensamiento, pero en un contacto con la realidad dentro de un campo vital, en el interior del cual las cosas se nos ofrecen primero como objeto de experiencia que como objeto de conocimiento. Es desde el interior de nuestra experiencia originaria del mundo (el mundo de la vida), desde donde constituimos nuestros objetos de investigación.

Así pensada la práctica científica, se hace posible entenderla no sólo en su dimensión estrictamente teórica (lógica de la construcción teórica o de validación de teorías), sino desde su intencionalidad, en su significación antropológica y en sus implicaciones ético-políticas concretas. A su vez, la labor de pensar es una renovada marcha hacia el fundamento, lo que el filósofo quiere y puede transmitir es aquella convicción inicial de que siempre hay algo más allá de lo que esta ante nuestros ojos y que sólo el que se plantee el problema de las falsas evidencias puede despertar en él la sorpresa ante las cosas y poner en marcha el acto de reflexión.

Estas consideraciones sobre los tipos de conocimiento, sus relaciones y diferencias requieren ser complementadas con un señalamiento en torno a la interdisciplinariedad. En efecto, todo lo dicho, si bien presenta la utilidad de 
disponer de una base conceptual para el esquema de organización de los tipos de conocimiento, corre el riesgo de sugerir que tales campos se dan en estado puro en el flujo diario del trabajo académico. Por el contrario, la experiencia internacional y nacional nos ofrece ejemplos de conjugación, en los planes de estudio, de diferentes combinaciones de saberes para el logro de la formación de una persona y de esfuerzos por incentivar la inter y transdisciplinariedad en las funciones de docencia y de investigación. Adicionalmente debe tenerse en cuenta que al presentar de modo analítico las diferentes formas del saber no debe perderse de vista su articulación y unidad última. Por el contrario cada vez más las ciencias sociales son más respetuosas de la naturaleza y, a su vez, las ciencias naturales van conquistando una visión del universo como inestable e impredecible y activo no sujeto de modo pasivo a las condiciones de la observación y del observador. Cada vez crece la convergencia entre un tipo de ciencias y otro desdibujándose en la misma medida el prejuicio ideológico de su separación, bajo el presupuesto de la existencia de un hiato insuperable entre naturaleza y cultura. Tal relación va aumentando en la medida en que se estudian sistemas complejos. Cada vez es más perentorio reconocer que - como lo señala I. Wallerstein - venimos de un pasado social de certezas en coflicto, relacionadas con la ciencia, la ética o los sistemas sociales, a un presente de cuestionamiento sobre la posibilidad intrínseca de la certeza. Quizá estamos presenciando el fin de un tipo de racionalidad (WALLENSTEIN, 2007).

\section{Niveles de formación}

En relación con los niveles de formación es necesario señalar que estos constituyen el otro eje sobre el cual se caracterizaría la oferta educativa. Este comprende tres niveles diferentes que se explican por sí mismos: el nivel técnico, el nivel profesional y el nivel avanzado. La conjugación de estos ejes permite identificar la oferta que una institución en virtud e su misión tendría como criterio para conformar su oferta educativa.

Si se tiene en cuenta lo anterior, ¿Cuál sería, entonces, la arquitectónica del sistema de la Educación Superior? Como lo ilustra el esquema siguiente, se trata de esfuerzo por organizar de modo sistémico el servicio de la educación de tercer nivel en el país de modo que sea posible identificar identidades y diferencias entre las opciones de formación que ofrece, las instituciones que las brindan, lo tipos de conocimiento de que se ocupan, manteniendo entre sí verdaderas sinergias que permitan que como un todo el sistema cumpla con su finalidad y propósitos y en su interior las instituciones con sus intereses propios tanto en el sector público como en el privado. 


\section{Tipología de las instituciones de educación superior}

En consecuencia de lo dicho, el Sistema de Educación Superior de Colombia está integrado por dos tipos de instituciones, a saber:

a) Institutos Técnicos de Educación Superior y

b) Universidades. Algunas de estas últimas, pueden ser universidades tecnológicas ${ }^{27}$.

Institutos Técnicos de Educación Superior. Estas instituciones tienen como finalidad ofrecer formación técnica superior en áreas ocupacionales específicas y de formación profesional. Para ello, cuidarán de desarrollar procesos de formación afines al método científico y contarán con una estructura orgánica correspondiente a su tamaño y complejidad. Estas instituciones adquieren su rostro propio a través de proyectos educativos (PEI) articulados con reglas de juego precisas, centrados en lograr competencias generales, específicas y sociales apropiadas para diversos campos laborales. Así mismo, procuran ofrecer una formación integral de sus estudiantes que permite la formación analítica y crítica de sus egresados. Estas instituciones están autorizadas para adelantar programas académicos de naturaleza práctica, sin perjuicio de las aspectos humanísticos implicados en los procesos de formación.

Universidades. Estas instituciones tienen como finalidad la generación de nuevo conocimiento en el campo básico y aplicado; ofrecer una formación interdisciplinaria dirigida a la integración del saber desde el punto de vista teórico y metodológico; otorgar formación profesional específica para distintas carreras para beneficio de la persona y de la sociedad. Las universidades deben desarrollar sus actividades en una variedad de profesiones y disciplinas no afines. Estas instituciones están autorizadas para adelantar programas de naturaleza tecnológica y científica, tanto como aquellos relacionados con las humanidades, el arte y la filosofía.

Universidades Tecnológicas. Estas instituciones constituyen un subconjunto de las anteriores y tienen como finalidad ofrecer programas académicos de naturaleza tecnológica y de nivel profesional y avanzado hasta maestrías de profundización; otorgar una formación profesional específica para distintas carreras y disponer de una estructura orgánica correspondiente. Para el logro de sus propósitos de formación deberán disponer de una unidad de ciencia básica que provea los saberes correspondientes a las tecnologías en las que trabaja.

27 Una vez más debemos dejar abierta la posibilidad de la existencia de instituciones de carácter tecnológico, no necesariamente denominadas universidades. Este aspecto deberá ser objeto de un análisis posterior sobre la base de la experiencia internacional. 
En tanto que ostentan el nombre de universidades, estas instituciones tendrán como finalidad el desarrollo de la ciencia aplicada, aspecto que ha de formar parte explícita en la formulación de su misión.

Hacia el futuro, cada institución asume su propia identidad y responde por ella a través del Sistema de Aseguramiento de la Calidad. A su vez, CONACAES y el CNA ajustarán sus estándares a la nueva tipología resultante y a las exigencias y expectativas que tanto el nuevo escenario, como las normas y la sociedad tienen de cada una de ellas ${ }^{28}$.

Las actuales Instituciones Tecnológicas podrán tener un cambio en su personería jurídica, mediante procesos de acreditación tal y como ya lo había definido la Ley 30 de 1992, y en un tiempo que la norma ha de determinar ${ }^{29}$. En este caso, se trataría de una medida transitoria.

A su vez, las Instituciones Universitarias, sobre cuya dinámica de funcionamiento, alcance y límites actuales existen pocos o ningún estudio analítico, podrían cambiar su carácter académico, a a través de un proceso de acreditación debidamente reglamentado.

\section{Gráfica 5}

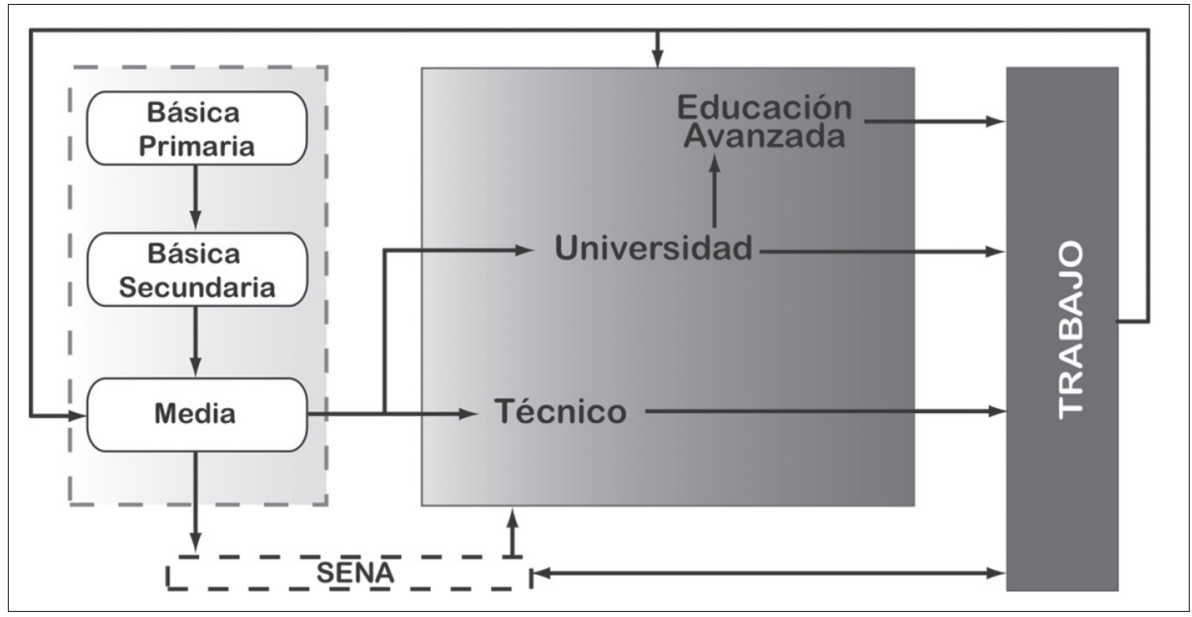

28 La diferencia central de esta propuesta radica en que conlleva claridad conceptual sobre campos de acción, crea condiciones para propiciar las características del sistema que se busca establecer, cada institución se ubica dentro de la tipología donde quiere pero responde por su opción a través de la acreditación y no se ofrece al país una tipología a priori que no consulta la realidad y obliga a las instituciones a entrar en un proceso que va de ser institución técnica hasta universidad sin llenar las condiciones que garanticen la calidad de los servicios que ofrecen.

29 También podría pensarse en la posibilidad de que estas instituciones existan de forma independiente pero en la medida en que cumplan con la oferta de programas acordes con la naturaleza de la tecnología en el mundo de hoy. 
De igual modo, el Sistema propuesto busca ser flexible, asumir la educación por ciclos y a lo largo de la vida, generando aperturas muy claves para el presente como son: la acción del SENA y las demandas de los mercados laborales; todo al servicio de un incremento de la pertinencia y calidad del servicio que se presta al país.

La articulación con el SENA no significa una inclusión de éste en el Sistema de Educación Superior sino el establecimiento de sinergias entre el potencial que esta institución tienen en el presente con las urgencias del sistema de la Educación Superior. En términos jurídicos, como lo previó la Ley 30, en materia académica los programas del SENA deben obedecer a los criterios fijados por la Ley que rige el Sistema de la Educación Superior en el país.

A su vez, se reconoce la existencia de instituciones que no forman parte del Sistema formal de Educación Superior y que en la actualidad ofrecen programas de educación del tercer nivel. A este respecto habrá necesidad de analizar la conveniencia de que estas formen parte del sistema o que se establezca para ellas una legislación apropiada. Se trata de instituciones tales como las Fuerzas Militares y de Policía, sindicatos, Academias, sociedades científicas, Asociaciones Profesionales, Gremios, IPSs, entre otras.

\section{CONCLUSIÓN}

Considerar el tema de la tipología de las instituciones que establece la Ley 30 de 1992, aunque constituye sólo un tópico de los cambios necesarios, tiene un impacto grande en el cuerpo de la norma. Como se señaló más arriba, su modificación trae consigo la necesidad de repensar el Sistema en su conjunto; de modo particular en lo relacionado con la manera como se definen las relaciones del Estado con la educación superior; los alcances y límites de la autonomía y el arreglo institucional de los organismos encargados del fomento, inspección, control y vigilancia del servicio público de la educación superior. Conscientes de esta salvedad necesaria, el texto ha tratado de ofrecer elementos de juicio específicos que puedan servir como temas de discusión en el proceso de la reforma en relación con la tipología existente.

Los cambios sugeridos se basan en un diagnóstico que se hace en una doble dirección: a- El comportamiento actual del Sistema de la Educación Superior en tópicos asociados a la tipología de las instituciones y b- Una presentación de los efectos prácticos que la tipología establecida por la Ley ha tenido en el funcionamiento de los programas académicos y en general en las características 
de la oferta, en el terreno de las denominadas modalidad técnica y tecnológica y con relación a las universidades.

Es desde este horizonte que emerge la necesidad de procurar con la reforma solucionar algunos aspectos que se desprenden directamente de la tipología; y otros a los cuales la reforma en este punto contribuiría a subsanar y que son de carácter más global. Entre los primeros merecen especial atención que el denominado Sistema de Educación Superior, no es un "sistema" ni funciona como tal; es, más bien, un conglomerado de instituciones que hacen una oferta a los mercados que atienden con incidencias negativas sobre la demanda; la articulación del sistema de educación superior con su niveles previos es muy débil y no propicia la movilidad estudiantil; cada tipo de formación que ofrece el sistema tiene un techo que impide la transferencia entre ellos; la formación técnica y tecnológica, en general, no es una opción prevalente entre los futuros usuarios y en el imaginario social parecería ser una "opción de segunda clase".

La tipología establecida en la Ley 30 de 1992 ofrece un arreglo "a priori" de las instituciones a partir del cual se les autoriza el tipo de programas y niveles que pueden atender; pero en la práctica, y con base en normas posteriores al 1992, la diferencia de ofertas ha venido desapareciendo hasta perder identidad y especificidad con relación a ls instituciones que las hacen. Tanto es así, que el mercado dispone de pocos elementos para diferenciar los tipos de formación que ofrece el sistema. Al no haber claridad en las ofertas, tampoco la hay en la definición misma de universidad y su diferencia con otros esquemas de formación, más aún, parecería que el Sistema de Educación Superior es una realidad homogénea compuesto por instituciones, de las cuales se predica que son diferentes, pero que la norma las considera análogas, tanto que al predicar la autonomía, que la Carta Política reconoce sólo a las universidades, se las aplica a todas las demás con el enunciado de que "son también autónomas en su respectivo campo de acción". Adicionalmente, la norma predica que son universidades las que ya son (aunque no lo sean, según las exigencias que histórica y conceptualmente debe tener una "universidad"). Estos son algunos de los aspectos centrales que las ideas aquí expuestas contribuyen a enfrentar y que subyacen a la propuesta.

En consecuencia, se trata de ofrecer un esquema de ordenamiento de las instituciones, o tipología, basado en una articulación pertinente de los tipos institucionales y de programas existentes Este ordenamiento permite que cada institución con base en su naturaleza y en lo que por vocación propia quiere ser, configure una oferta y responde por ella ante el Estado, la sociedad y los usuarios. Este doble criterio de ordenamiento permite pensar en la existencia 
no excluyente de dos tipos de instituciones de educación superior. De una parte, instituciones de carácter técnico y las universidades. Algunas de estas últimas pueden denominarse, por vocación propia, universidades tecnológicas.

La Ley de Educación Superior, podría ser una de carácter estatutario y vendría acompañada de dos más referidas, la primera a las universidades y la segunda, para regular la prestación del servicio en otras modalidades de educación superior tales como: La educación técnica, educación virtual, educación a distancia, la educación especial y otras. $\mathrm{O}$, en caso contrario, una sola Ley en la que se distinga claramente, en capítulos diferentes la normatividad propia de las universidades y la que correspondería a otras formas de educación postsecundaria o superior no universitaria.

Por su parte, las instituciones denominadas en la actualidad, tecnológicas, mediante el sistema de educación por ciclos, podrán reordenar su oferta educativa actual como primer ciclo de las ingenierías o mediante un proceso de acreditación solicitar en su momento un cambio de su personería jurídica, o, finalmente se instituciones centradas clara y distintamente en lo tecnológico, sin considerarlo como un paso intermedio para la obtención del título de ingeniero. La formación que otorgan estas instituciones, dentro del nuevo esquema, no necesariamente es un ciclo "propedéutico" de la formación en las diferentes ingenierías que puede ofrecer el Sistema de Educación Superior ${ }^{30}$. Las instituciones universitarias serán susceptibles de una redefinición de su carácter en conformidad Con su opción propia y mediante el proceso de acreditación correspondiente.

Para terminar, también se pueden mencionar otras externalidades positivas de la reforma de la tipología de las instituciones. En efecto, al mejorar el carácter sistémico de las formas de operación de las instituciones, se favorece la movilidad estudiantil; se articula mejor el nivel de formación superior con el previo que comprende la básica secundaria y media, aprovechando de modo creativo la acción del SENA en materia de educación técnica y posibilitando, inclusive, que instituciones de enseñanza media puedan ofrecer, en convenios con el SENA, formación técnica en ramas específicas, previa obtención por parte de este último organismo de los registros calificados correspondientes. De igual modo, se contribuye de modo directo a recuperar el valor de la formación técnica y tecnológica en el país como instrumento estratégico en materia de formación del talento humano que se requiere. Finalmente, la nueva norma permitiría que las universidades puedan asumir con autonomía responsable su tarea respecto

30 Este aspecto necesita una mayor elaboración. No debe olvidarse que esta formulación de la propuesta es una primera aproximación que podrá enriquecerse con los actores del sector. 
de la producción de un bien público, como es el de al educación, respondiendo ante la sociedad y el Estado por lo que dicen ser, a través del Sistema de Aseguramiento de la Calidad de la Educación Superior; replanteando, claro está, los actuales modelos teórico-metodológicos con los que trabaja tanto SACES a través de CONACES, como el $\mathrm{CNA}^{31}$ en virtud de haber sido concebidos y estructurados en otros contextos ya sobrepasados por el escenario actual en el que operan las instituciones de educación superior en el país y para adecuarlos a la nueva normatividad.

\section{REFERENCIA}

ARGENTINA.Ley n. 26.206 de Educación Nacional. Argentina. 2006. BARNES, B. (Ed.). Estudios sobre sociologia de la ciencia. Madrid: Alianza Editorial, 1980. p. 79 y ss.

BRASIL.Ley N. 9.394 de Educación Superior. Brasil, 1996.

BRUNNER, José Joaquín. Aseguramiento de la calidad y nuevas demandas sobre la Educación superior en América Latina. En: SILVA, Luis Enrique Orozco. Educación Superior: problema global y respuesta nacional. Bogotá, 2001.

\section{BRUNNER, J-J. et al. El Informe de la educación superior en} iberoamérica. Santiago de Chile: CINDA-UNESCO, 2007.

CELIS, E. Pregrados profesionales en áreas tecnológicas. Alternativa a la educación en ingeniería por ciclos de la Ley 749. Bogotá, 2006.

(Documento)

CHILE.Ley N. 20.129 por la cual se crea el sistema de Aseguramiento de la calidad de la Educación superior. Santiago de Chile, 2006.

\section{CLARK, B. Las universidades modernas, espacios de investigación y docencia .México, 1989.}

31 En los últimos años se ha hecho un esfuerzo por atenuar algunos de estos aspectos críticos de la normatividad actual a través de Decretos y Resoluciones. Será necesario revisar el contenido de los mismos para incorporar lo mejor de dicho esfuerzo, en materia de flexibilidad, educación por ciclos, política de créditos, entre otros. 
CLARK, B. Las universidades modernas espacios de investigación y docencia. México: Nueva Imagen, 1997.

ESPAÑA.Ley Orgánica de Educación. España, 2006.

GIBBONS, Michel. La nueva producción del conocimiento. Barcelona: Pomares-Corredor, 1997.

GIDDENS, A. Nuevas reglas del método sociológico. Amorrortu: Bs. As., 2003.

GLOBAL UNIVERSITY NETWORK FOR INNOVATION. La educación superior en tiempos de cambio. Nuevas dinámicas para la responsabilidad social. Madrid: GUNI Ediciones Mundi- Prensa, 2009.

GÓMEZ, Víctor Manuel. Hacia la diferenciación y la especialización en la educación superior. Propuesta para el caso de Colombia. Educación Superior y Sociedad, Bogotá, v. 2, n. 2, [s.d.].

HABERMAS, J. Conocimiento e interés, science et téchnique comme idéologie. París: Gallimard, 1973.

HORKHEIMER, M. Teoría tradicional y teoría crítica. Buenos Aires: Amorrortu, 1974.

ICFES. Programas de enseñanza conducentes a diplomas en carreras de tecnología. Bogotá, 1972.

ICFES. Educación técnica y tecnológica en Colombia: diagnóstico y recomendaciones. Bogotá, 1997.

ICFES. Bases para una política de Estado en materia de educación superior. Bogotá, 2001.

KANT, M. Crítica de la razón de juzgar. París: J. Vrin, 1989.

KHUN, Thomas. Estructura de las revoluciones científicas. México: F.C. E., 1985.

LADRIÉRE, Jean. El reto de la racionalidad. Madrid: Sígueme, 1989.

LINARES, Patricia. La autonomía universitaria expresión esencial del estado democrático de derecho. Impreso. Bogotá, 2010. 
LUCIO, Ricardo; SERRANO, Mariana. La educación superior: tendencias y políticas estatales. Bogotá: Universidad Nacional de Colombia, 1992. BOGOTÁ.MINISTERIO DA EDUCACION NACIONAL. Decreto 80 de 1980. Bogotá. . Ley 30 de 1992. Bogotá. . Ley 749 de 2002. Bogotá.

MORIN, Edgar. Los siete saberes de la educación superior. París: UNESCO. 1992.

MOUFFE (Ed.). Deconstruction and pragmatismo. London: Routledge, 1996.

OROZCO SILVA, Luis Enrique. Elementos para una reforma de la educación postsecundaria. Documento base de la reforma, 1990.

OROZCO SILVA, Luis Enrique. La educación superior. Desafío global y respuesta nacional. Bogotá: Universidad de los Andes, 2001a. 2v.

OROZCO SILVA, Luis Enrique. Formación integral: mito y realidad. Bogotá: Universidad de los Andes/Editorial Tercer Mundo, 2001b.

OROZCO SILVA, Luis Enrique et al. La universidad a la deriva. Bogotá, 1989.

OROZCO SILVA, Luis Enrique. Problemas de método de las ciencias sociales. Col. Apuntes de Clase. I y II. Bogotá: Universidad de los Andes, 2007.

OROZCO SILVA, Luis Enrique. La dualidad Agencia-Estructura y sus implicaciones metodológicas. En: GIDDENS, Anthony (Org.). Apuntes de clase. Bogotá: Universidad de los Andes, 2009.

OROZCO SILVA, Luis Enrique. Ciencia(s) positiva y filosofía. En:

CAMPOS del saber. Universidad de los Andes. Bogotá, 1982. p. 141 y ss

OROZCO SILVA, Luis Enrique. Problemas de método en las ciencias sociales. Bogotá: Universidad de los Andes, 2006.

OROZCO SILVA et al. La cobertura. Eje de la política educativa 20022008. Bogotá: Universidad de los Andes, 2009. 
ORTEGA Y GASSET, J. Misión de la Universidad. Revista de Occidente, Madrid, p. 35 y ss., 1982.

REICH, Robert B. El trabajo de las naciones. México: Vergara, 1993.

UNESCO. New technologies in higher education. París, 2007.

MARMOLEJO F. Internacionalización de la educación superior. Algunas reflexiones. México: Educación Global, 2007.

WALLENSTEIN, I. Abrir las ciencias sociales. México: Seculo XXI, 2007. 